\title{
Multi Directional Pushover Analysis of Irregular Masonry Buildings without Box Behavior
}

\author{
Philip Kalkbrenner $^{\mathrm{a}, *}$, Luca Pelàa ${ }^{\mathrm{a}}$, Cristián Sandoval ${ }^{\mathrm{b}}$ \\ ${ }^{a}$ Department of Civil and Environmental Engineering, Universitat Politècnica de Catalunya (UPC-BarcelonaTech), Jordi Girona 1-3,08034 \\ Barcelona, Spain \\ ${ }^{b}$ Department of Structural and Geotechnical Engineering and School of Architecture, Pontificia Universidad Católica de Chile, Casilla 306, \\ Correo 22, Santiago, Chile
}

\begin{abstract}
This paper proposes the use of multiple nonlinear static analyses for the seismic assessment of irregular masonry buildings without box behavior. The methodology consists in executing a series of sequential pushover analyses on the spatial model of the building by rotating the horizontal loading direction from $0^{\circ}$ to $360^{\circ}$. The so-called multi directional pushover analysis allows a more realistic evaluation of the seismic vulnerability, since it can represent a higher number of possible failure mechanisms than in the conventional pushover analysis restricted to the two "principal" directions of the structure. The application of the methodology to a highly irregular masonry building located in Chile shows that the detected failure mechanisms are in very good agreement with those derived from nonlinear dynamic analysis, as well as with the damage experienced by the structure after the earthquake of February 27, 2010 (Mw 8.8).
\end{abstract}

Keywords: Masonry Structure, Nonlinear Static Analysis, N2 method, Nonlinear Dynamic Analysis, Structural Irregularity, Flexible Diaphragm, Local Collapse Mechanism, Out-of-Plane Mechanism, Seismic Assessment, Earthquake Engineering

\section{Introduction}

Masonry is one of the oldest construction materials and several design and calculation methods have been developed to evaluate its structural behavior. A major portion of all the built structures worldwide are made of masonry and a substantial part belongs to the architectural heritage which has to be preserved due to its beauty and cultural value.

Nowadays the use of numerical methods is customary in the field of structural engineering. Many researchers have proposed numerical methodologies to simulate the complex material behavior of masonry. A general overview of modeling techniques for masonry structures is summarized in [1]. A special attention is paid on the finite element (FE) approaches which offer a wide range of modeling strategies. Micro-modeling [26] distinguishes among the masonry components (units

\footnotetext{
${ }^{*}$ Corresponding author

Email address: philip.kalkbrenner@upc .edu (Philip Kalkbrenner)
}

Preprint submitted to Engineering Structures and joints) and is very accurate, but still too expensive in terms of computation time when applied to large structures. Macro-modeling [7-13] represents the material as an homogenized continuum and thus offers wide applicability to real scale structural applications.

Masonry structures have shown to be very vulnerable to seismic actions. Several methods have been proposed to deal with the assessment of their seismic safety. The available approaches differ in the level of complexity based on the assumed fundamental hypotheses. Even though linear methods have been used in the past decades, nonlinear methods have been preferably applied to the seismic analysis of masonry structures.

The nonlinear static analysis (NSA), also known as pushover analysis, models the earthquake action as a system of seismic equivalent lateral forces increasing monotonically during the analysis. Another possibility is offered by nonlinear dynamic analysis (NDA) that can be performed by regarding complete earthquake acceleration time histories. This last approach is certainly very accurate but its computation time is higher than in the NSA. A recent study [14] has shown that 
for simple symmetric masonry buildings, the capacity curve of the pushover analysis with mass proportional lateral loading pattern, expressed in terms of the relationship between the structure's base acceleration and top displacement, provides a good agreement with the envelope of the hysteretic loops from NDA. Another recent investigation [15] has presented a discussion on the use of NSA and NDA for the performance based assessment of existing masonry buildings. Several recent works provide examples of applying pushover analysis to churches, fortresses and towers, e.g. [16-19]. A parametric study of the important effect of material properties assumption on the results derived from nonlinear seismic analyses is reported in [20].

Nonlinear static and dynamic methods have been employed to assess the seismic behavior of masonry buildings without box behavior $[21,22]$, i.e. presenting flexible floors and/or deficient floor-to-wall or wall-to-wall connections. These studies have shown limitations and possibilities for the different approaches to account for the lacking box behavior in the evaluation of the seismic response of the building.

Existing masonry structures often exhibit structural irregularities, as possible consequence of historical interventions and subsequent modifications to their layout. Such irregularities, which can be observed both in plan and in elevation, are frequent in historical masonry structures, especially in those of the urban centers. Static analysis methods present several limitations for this class of buildings, since they cannot represent properly the complex 3D dynamic response during the earthquake.

This paper investigates the possibility to use multiple nonlinear static analyses to assess the seismic behavior of irregular masonry structures without a box behavior. The research proposes the use of a series of pushover analyses conducted by rotating the loading direction from $0^{\circ}$ to $360^{\circ}$. This working strategy allows to evaluate the seismic response of the building along several directions, in addition to the two "principal" loading directions assumed in conventional pushover analysis of regular buildings.

The so-called multi directional pushover analysis (MDPA) is applied to a very complex building, the Palacio Pereira located in Santiago de Chile. This historical masonry building presents structural irregularity both in plan and in elevation, and exhibited structural deficiencies (flexible timber floors, inadequate floor-to-wall and wall-to-wall connections) when it was struck by 2010 Chile earthquake. The Palacio Pereira is analyzed by making reference to a complete 3D nonlinear macromodel within the FE method. Eight loading directions were considered for the NSAs. The results of the MDPA are compared with those derived from response spectrum analysis (RSA) and NDA by using respectively the inelastic acceleration spectra and seismic record of the 2010 Chile earthquake. The MDPA methodology shows to provide results in good agreement with the outcomes of NDA, as well as with the actual damage experienced by the structure after the earthquake of February 27, 2010 (Mw 8.8). These results demonstrate that the MDPA could be helpful in detecting all the possible local collapse mechanisms that are likely to occur in irregular masonry buildings without box behavior.

\section{Methodology}

The nonlinear dynamic analysis (NDA) is currently the most accurate procedure for the seismic assessment of masonry structures, but the nonlinear static analysis (NSA) is usually preferred in common practice due to its easier implementation and lower computational cost. However, the conventional NSA presents restrictions about the applicability to irregular masonry buildings whose dynamic behavior is the result of the complex interaction among local vibration modes. In addition, conventional pushover procedures show important limitations when applied to structures without box behavior.

This research presents a novel approach based on the execution of multiple NSAs along different geometrical orientations of the investigated building. The objective is to obtain an improved representation of the local damage and failures, with a specific attention to out-of-plane mechanisms that show to be the more recurrent in irregular masonry buildings without box behavior. This section discusses the operation of the proposed multi directional pushover analysis (MDPA) technique, after having presented an overview of available NSA approaches, including both conventional and updated techniques to deal with structural irregularity.

\subsection{Overview of Available Pushover Procedures \\ 2.1.1. Conventional Approaches}

The conventional NSA approach evaluates the seismic capacity by increasing monotonically an invariant lateral load pattern applied to the structural model. The gradual increase of horizontal loads leads to progressive damage, and thus to gradual decrease of the stiffness until reaching the collapse condition. The Eurocode 8 (EC8) [23] recommends the use of the "uniform" and "modal" loading patterns in NSA. The first consists in lateral forces proportional to mass regardless of elevation, while the second is proportional to lateral force distributions given by previous elastic (modal) 
analysis. The applicability of the conventional pushover approach is restricted to structures vibrating predominantly in the first mode and with time-independent deformation shape. For this reason, the N2 method [24], suggested by EC8 to determine the seismic demand, is applicable only to structures fulfilling specific requirements for plan and elevation regularity. A recent research [25] suggests the application of a proper lateral load pattern in the pushover analysis of masonry buildings with low participating mass in the first mode.

The evaluation of the seismic capacity in NSA refers to the relationship between the total base shear and the displacement of a representative control node. The choice of the control node is straightforward in buildings with rigid floors well connected to the walls. For such cases, the EC8 suggests the location of the control node to be at the center of mass at the top floor level. However, the choice of a suitable control node becomes difficult in NSA of irregular buildings with flexible diaphragms $[25,26]$ since the lack of box behavior leads to local damage and failure mechanisms [22, 27-29]. Recent works propose the selection of different control nodes in NSA in order to follow the response of the most critical structural members during the analysis $[17,25,30]$.

\subsubsection{Extension to Irregular Buildings}

The EC8 proposes a simplified procedure for the estimation of the torsional effects, also known as extended N2 method [31], consisting in the definition of a proper amplification factor for the displacements, based on the results of an elastic modal analysis. The method combines the results from a NSA of a 3D structural model of the irregular structure with those from a linear dynamic (spectral) analysis, in order to estimate the torsional amplifications. The extended N2 method has been applied to the pushover-based seismic analysis of asymmetric reinforced concrete $(\mathrm{RC})$ framed structures with rigid floors [31, 32]. Available standards are in need of improvement in order to provide practical specifications for the seismic analysis of irregular masonry buildings.

Several researches have addressed the possibility of extending the applicability of conventional pushover procedures by trying to overcome some of their intrinsic limitations [33]. The modal pushover analysis (MPA) [34] considers the inertia force distributions for different modes with the aim of including also the contributions from higher vibration modes. These modal contributions are then combined by using the Square Root of the Sum of Squares (SRSS) or Complete Quadratic Combination (CQC) rules. The adaptive pushover analysis (APA) [35] considers an adaptive force distribution that is updated during the analysis according to the variable distribution of inertia forces given by the stiffness degradation and evolving damage. Recent works on seismic analysis of masonry buildings with flexible diaphragms have presented critical comparisons between the results from NDA and MPA or APA [14, 22, 26] showing that these non-conventional pushover procedures should be used with caution since they may not provide meaningful improvements in terms of load-displacement diagrams and failure mechanisms.

\subsection{Multi Directional Pushover Analysis}

\subsubsection{Background}

The NDA on spatial models of buildings considers the two horizontal components of the seismic action acting simultaneously. This allows NDA to evaluate in a direct manner the complex tridimensional response of structural systems subjected to multi directional earthquake ground motions.

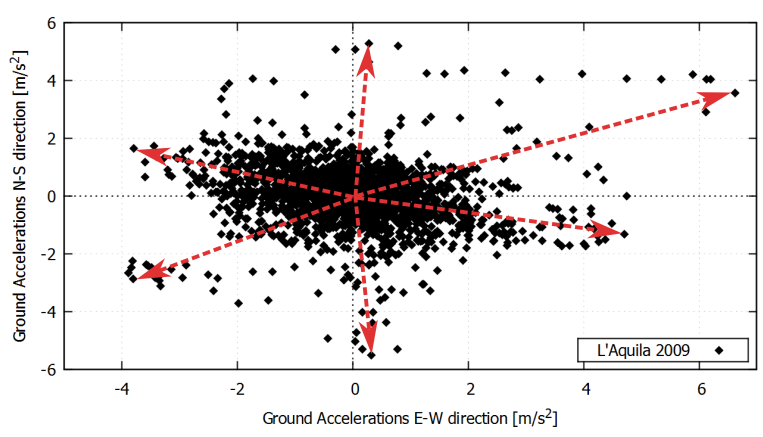

(a) L'Aquila 2009 recorded at Via Aterno - Centro Valle

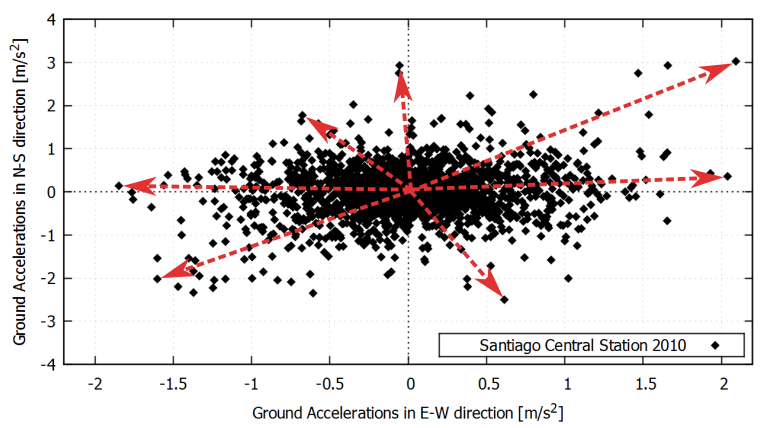

(b) Chile 2010 recorded at Santiago Central Station

Figure 1: Examples of East-West vs. North-South acceleration relationship for two recorded earthquakes

Figure 1 shows the directional variability of the ground accelerations recorded during the $\mathrm{Mw} 6.3$ L'Aquila earthquake of 2009 [36] and the Mw 8.8 Chile earthquake of 2010 [37, 38]. The plot of the East-West versus the North-South acceleration values at the same 
time instant provides a point cloud, with some orientations characterized by larger responses, as shown by the arrows in Figure 1. This visual plotting shows the multi directional character of real earthquake ground motions and suggests how NDA can directly account for it in the evaluation of the seismic vulnerability.

The NSA procedures presented in Section 2.1 cannot address the aforementioned issue. The NSA of spatial models of buildings considers increasing horizontal loading patterns acting separately along the "principal" directions of the buildings, e.g. the longitudinal/transversal or North-South/East-West directions. This constitutes a strong limitation for the case of irregular buildings without box behavior, being not possible to include within the procedure the evaluation of the effect of bidirectional loading on structural members prone to local damage and failure mechanisms.

Recent works available in the literature have investigated the extension of the conventional NSA procedures to tridimensional analysis of structures subjected to bidirectional components of ground motions [32, 3941]. These researches have carried out bidirectional NSA, i.e. by considering two simultaneous loading patterns along perpendicular horizontal directions, in the seismic assessment of cable-stayed bridges, irregular $\mathrm{RC}$ frames, RC core wall tall buildings and RC chimneys, respectively.

Two researches $[42,43]$ have recently addressed the topic of multi directional pushover-based seismic assessment applied to masonry buildings. Both investigations have considered a discrete macro-element modeling technique for the analysis of an historical palace damaged by L'Aquila earthquake, and a brick masonry structure prototype tested in the laboratory. The first case study is a building that underwent seismic retrofitting interventions before L'Aquila earthquake and thus exhibited a global box behavior with overall resisting response after the earthquake, as also confirmed by the numerical analyses. The second case study is a laboratory specimen including a main gable wall with two returns, i.e. an experimental prototype of a structural member with a predominant out-of-plane failure response.

\subsubsection{Proposed Procedure}

The present research aims to contribute to further developments on multi directional pushover procedures for the seismic analysis of masonry buildings. This section presents the description of the different stages of the proposed methodology, while the following section will present its practical application to an irregular historical masonry building without box behavior. The considered real building has been chosen purposely in order to present a novel challenging case study of MDPA of a complex structure with prevailing out-of-plane mechanisms in case of earthquake. The working steps of the proposed MDPA are listed in the following.

Step 1: A spatial 3D FE model is developed with nonlinear constitutive laws for the materials. The modeling of diaphragms has to account for the actual stiffness of roofs and floors. In case that their rigidity is negligible and floor-to-wall connection is weak, the inplane tying effect can be neglected and the floors may be modeled as lumped masses at the level of stories in order to simplify the FE model.

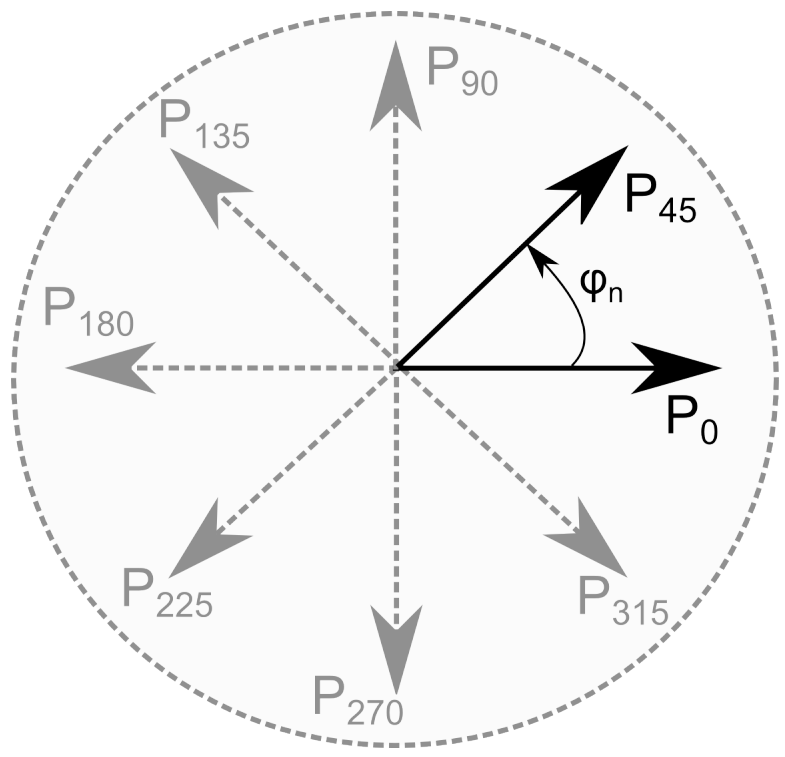

Figure 2: Proposal of basic directions to be considered in the multi directional pushover analysis

Step 2: The MDPA is applied to the spatial 3D FE model to determine the seismic capacity of the structure. The method considers multiple NSAs executed along different directions with respect to the plan of the building, after establishing an angle of variation $\varphi_{n}$ between subsequent orientations. This work, as a first approach to the topic, suggests to consider at least eight NSAs, i.e. to assume $\varphi_{n}=45^{\circ}$ (Figure 2), with horizontal loading patterns proportional to the distribution of the masses in the FE model (constant accelerations along the height). Future works may consider $\varphi_{n}=22.5^{\circ}$ or $\varphi_{n}=30^{\circ}$, depending on the complexity of the investigated case study until achieving a good compromise between computation cost and accuracy of results. 
Step 3: The control nodes to draw the loaddisplacement capacity diagrams are selected by carefully analyzing the most vulnerable structural members of the masonry building. For the case of irregular systems, the typical existence of different failure mechanisms leads to the choice of different control nodes. Out-of-plane displacements have to be controlled with caution in overturning walls of masonry buildings without box behavior.

Step 4: The nonlinear force-displacement relationship of the multi-degree of freedom (MDOF) system is plotted for the selected control node corresponding to the failure mechanism. The pushover curve of the MDOF system is transformed into the capacity curve of an equivalent single-degree of freedom (SDOF) system, by evaluating the transformation factor $\Gamma$ according to the $\mathrm{N} 2$ method:

$$
\Gamma=\frac{\sum m_{i} \Phi_{i}}{\sum m_{i} \Phi_{i}^{2}}=\frac{m^{\star}}{\sum m_{i} \Phi_{i}^{2}}
$$

where $m^{\star}$ is the mass of the equivalent SDOF system, $m_{i}$ is the mass of the $\mathrm{i}$-th node of the FE model and $\Phi_{i}$ is the normalized displacement of the i-th node. Since this factor shows to be very sensitive to the applied load pattern in NSA and the related deformed shape, this work considers the displacement shape $\Phi$ derived from the initial elastic stage of a pushover analysis with mass-proportional horizontal loading pattern and without gravity loads applied [25, 44]. The displacement shape is normalized to the highest control displacement. Within the framework of the proposed MDPA, different transformation factors $\Gamma$ are calculated for different NSA loading orientations, and this constitutes a novel contribution to the approach compared to previous studies considering a unique transformation factor for all the considered directions [42]. In particular, for a specific NSA loading orientation, the direction for the calculation of the transformation factor $\Gamma$ is that of the largest horizontal component (X or $\mathrm{Y}$ ) of the control displacement. For the specific case of masonry buildings without box behavior, e.g. the case study investigated in this paper, if the overturning mechanisms of walls are the most vulnerable, the out-of-plane displacement directions are considered for the calculation of the transformation factors $\Gamma$, see Section 3.4.1. The capacity curve of the equivalent SDOF system is expressed eventually in terms of its force $F^{\star}$ and displacement $d^{\star}$ :

$$
\begin{aligned}
F^{\star} & =\frac{F_{b}}{\Gamma} \\
d^{\star} & =\frac{d_{n}}{\Gamma}
\end{aligned}
$$

where $F_{b}$ and $d_{n}$ are the base shear force and the control node displacement of the MDOF system. The capacity curve of the equivalent SDOF system is evaluated only along the direction of the largest horizontal component (X or Y) of the control displacement. However, its shape is affected by the orientation of the loading direction with respect to the plane of the wall. Finally, the capacity diagram is expressed in the acceleration-displacement format by dividing the forces in the $F^{\star}-d^{\star}$ curve by the mass $m^{\star}$ of the equivalent SDOF system.

Step 5: The capacity curve showing the relationship between the base shear force and the displacement of the SDOF equivalent system is idealized by a bilinear method. The simplified elastic-perfectly plastic bilinear capacity curve for the equivalent SDOF system can be evaluated by engineering judgment and guidelines available in regulatory documents [45]. The ultimate displacement is identified in correspondence to a decrease of $20 \%$ of the maximum load capacity of the structure $[45,46]$. However, the execution of pushover analysis in the softening range is usually not straightforward in continuum FE models of masonry structures within the smeared crack approach, due to convergence problems related to the brittleness of the elements. For this reason, it is important to identify properly the ultimate displacement as the condition corresponding to the full development of the collapse mechanism in the FE structural model. The yield displacement is given by an energy equivalence criterion, i.e. by assuming that the areas under the actual and idealized force-displacement curves are equal [23].

Step 6: The performance point is obtained by comparing the seismic capacity of the SDOF system with the demand expressed by an inelastic response spectrum, as indicated in the procedure of the N2 method $[23,24]$. The displacement demand for the equivalent SDOF system is finally transformed into that of the MDOF system, using Equation 3. 


\section{Multi Directional Pushover Analysis of an Irreg- ular Building without Box Behavior}

\subsection{The Palacio Pereira in Santiago de Chile}

In the era of Chile's economic boom in the 1870 s, rich mine magnates bought properties in the center of the city of Santiago and constructed "Haciendas" which due to their imposing and neoclassical style more or less appeared like palaces ("Palacios"). One of these buildings is the Palacio Pereira which was commissioned by Luis Pereira, designed by the French architect Lucien Ambroise Hénault and constructed in 1872. Figure 3 shows the building from the exterior in 2013.

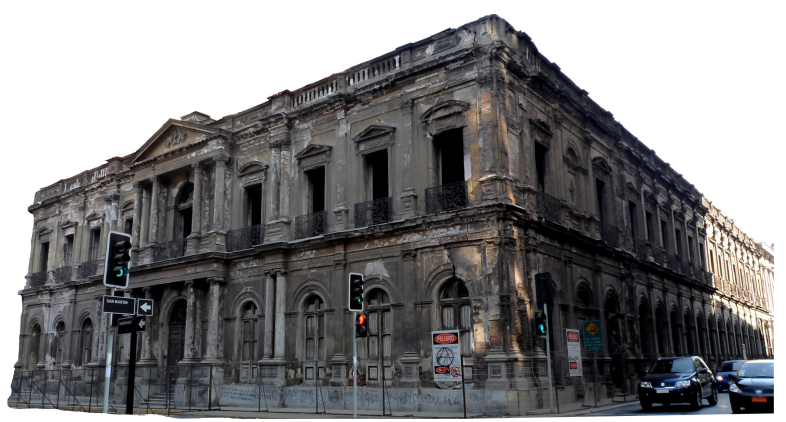

Figure 3: Exterior view of the Palacio Pereira in 2013 before the works of restoration

The Palacio Pereira is a two-story building made of unreinforced masonry composed of traditionally produced clay bricks with dimensions $0.40 \times 0.20 \times 0.06 \mathrm{~m}^{3}$ and lime mortar. Vertical loads are transmitted to the foundations by the $0.6 \mathrm{~m}$ thick load bearing walls, that act also as shear resisting elements in case of application of horizontal actions. The height of the complete building is approximately $10 \mathrm{~m}$. The floor and roof structures are made of timber members.

Figure 4 shows a schematic view in plan of the wall layout in first and second floor of the Palacio Pereira. As shown, the building is remarkably irregular in plan with a L shape, and also presents irregularity in elevation due to the presence of 2-storey volumes along with 1-storey ones surrounding the interior courtyard.

Several geometrical criteria provided by the EC8 [23] for building regularity do not comply with the construction characteristics of the Palacio Pereira:

- Plan Irregularity (EC8, section 4.2.3.2). The Palacio Pereira is not symmetric in plan and does not present any rigid diaphragm at floor and roof levels, since these structural parts are made of timber. The structural eccentricities $e_{0 x}$ and $e_{0 y}$ exceed by more than $30 \%$ the torsional radii $r_{x}$ and $r_{y}$, respectively.

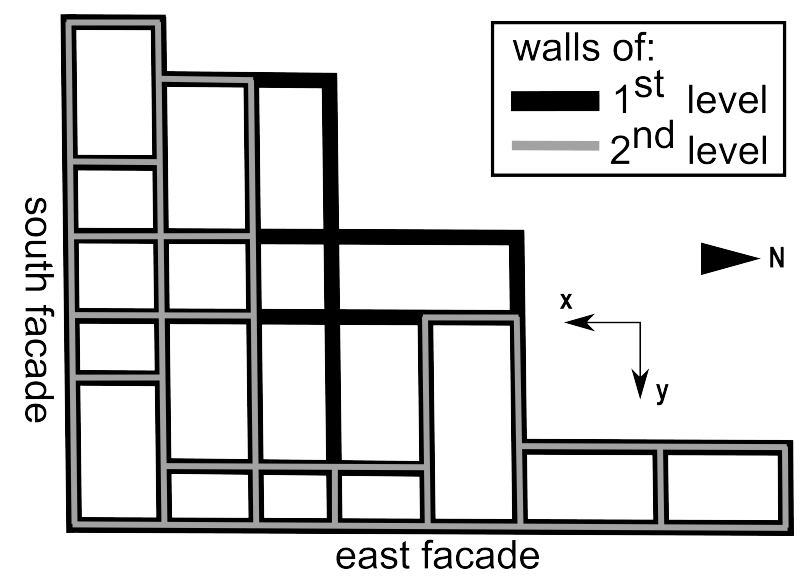

Figure 4: Plan view of the first and second floors' walls

The eccentricities $e_{0 x}$ and $e_{0 y}$ are the distances between the barycenters of mass and stiffness along the $\mathrm{x}$ and $\mathrm{y}$ direction, respectively. The torsional radii $r_{x}$ and $r_{y}$ are the square roots of the ratio of the torsional and the lateral stiffness in $\mathrm{y}$ or $\mathrm{x}$ direction, respectively. (Palacio Pereira: $e_{0 x}=3.24 \mathrm{~m}, e_{0 y}=1.79 \mathrm{~m}$, $0.3 r_{x}=0.91 m$ and $\left.0.3 r_{y}=0.79 m\right)$.

- Elevation Irregularity (EC8, section 4.2.3.3). The difference of translation stiffness is about $75 \%$ between the first and second levels of the structure. This specifies an abrupt change in elevation. Setbacks are present and in several parts they do not comply with the specifications from the standard.

The Palacio Pereira suffered demanding seismic actions during its lifetime. Two strong earthquakes in 1985 and 2010 caused severe damage to the building. Figure 5 shows large diagonal shear cracks at inner walls and above windows, as well as cracks at wall connections, due to the 2010 earthquake. Figure 6 shows sketches of the south and east facade and indicates the real existing damage in the two main facades of the Palacio Pereira after the 2010 earthquake, as analyzed by Sandoval et al. [37]. The highlighted areas display cracked parts of the structure. Even though many portions of the building were damaged, the entire structure is being restored to host cultural facilities.

\subsection{FE Modeling of the Building}

A 3D FE model was built for the analysis of the Palacio Pereira before the recent restoration, i.e. in the structural configuration struck by 2010 earthquake. All computations were carried out by using the FE software DIANA FEA [47]. Figure 7 shows the FE model of the 

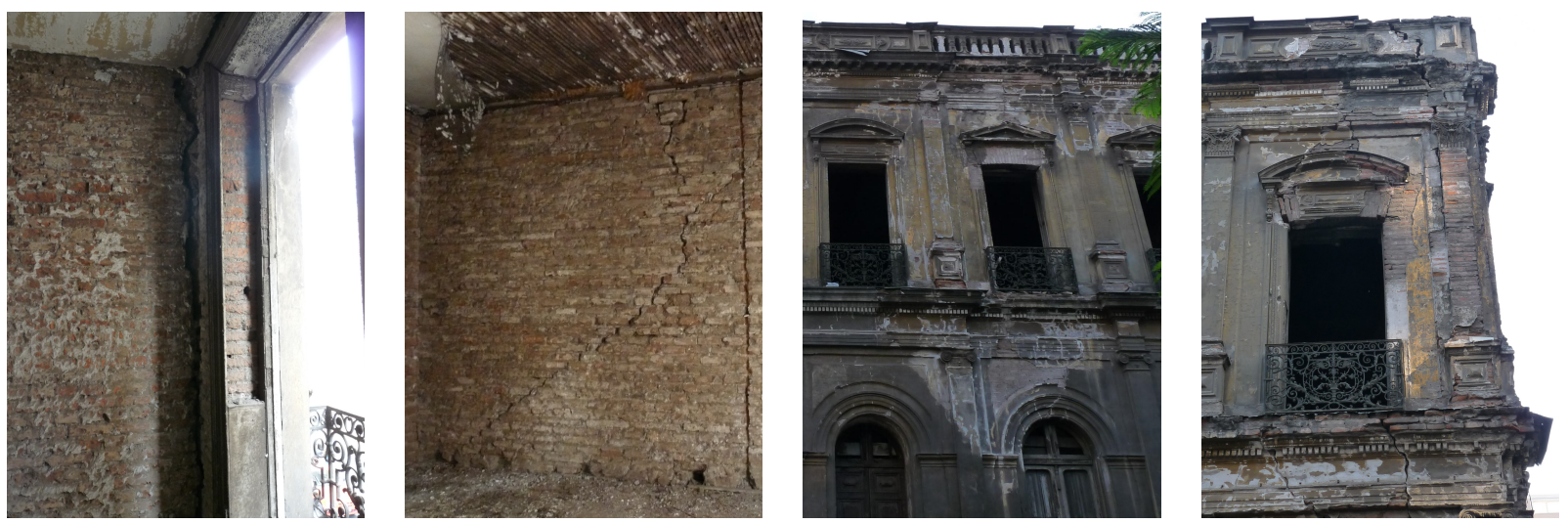

Figure 5: Damaged parts and cracked walls of the Palacio Pereira after the 2010 Chile earthquake

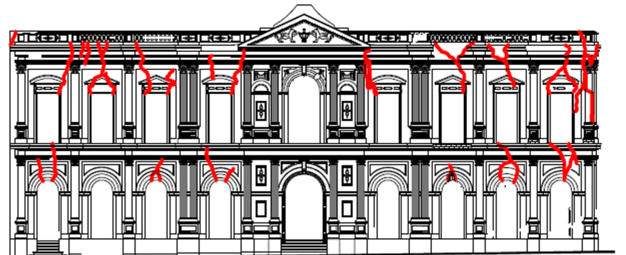

(a) South facade

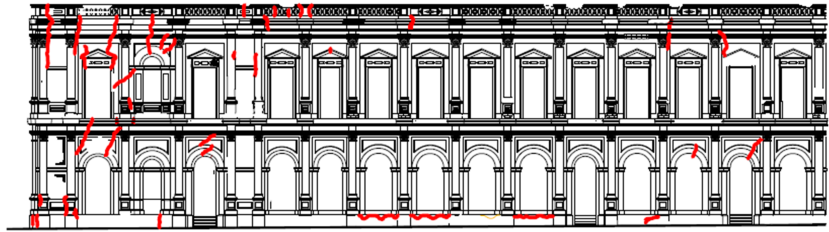

(b) East facade

Figure 6: Existing damage in the South and East facade analyzed by Sandoval et al. [37]

building. All the walls of the Palacio Pereira were modeled by shell elements, i.e. the triangular three-noded element T15SH and the quadrilateral four-noded element Q20SH, with an average element size of $0.5 \mathrm{~m}$. Threepoint in-plane integration is used for triangular elements , while $2 \times 2$ in-plane integration is used for quadrilateral elements. The three-point Simpson rule is used for through-thickness integration in the shell elements. The total number of nodes and elements is 14144 and 12597 , respectively. The FE model does not include any horizontal rigid diaphragm due to the flexibility of the roofs and floors existing in 2010. However, the corresponding masses of floors and roofs are added to the load bearing walls supporting the unidirectional floors. The model presents two horizontal levels of added masses in the form of distributed loads applied to the walls' nodes at the floor and roof levels. The distributed weight of the floors and the roof are $0.3 \mathrm{kN} / \mathrm{m}$ and $1.0 \mathrm{kN} / \mathrm{m}$, respectively. All base nodes of the walls are fixed, with both translation and rotation constrained.

The total strain based rotating crack model implemented in the DIANA FEA software is chosen for the masonry material. This constitutive model considers an exponential softening curve under tension and a

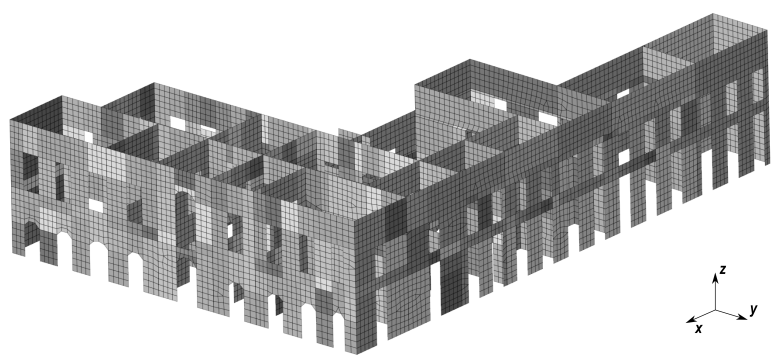

Figure 7: 3D Model of the Palacio Pereira for finite element analysis

parabolic softening curve under compression.

Table 1 shows the material properties applied in the FE model of the Palacio Pereira. Their values were calibrated through the numerical simulation of an in-situ shear test performed on a portion of an existing wall located at the first floor of the building [37].

Figure 8a shows the experimental setup of the insitu shear test executed on a $1.00 \times 2.00 \mathrm{~m}^{2}$ portion of the wall, reproducing two $1 \mathrm{~m}^{2}$ specimens one upon the other. The loading was applied by a 600 $k N$ force-controlled hydraulic jack, while four displacement transducers were used to measure the diagonal 


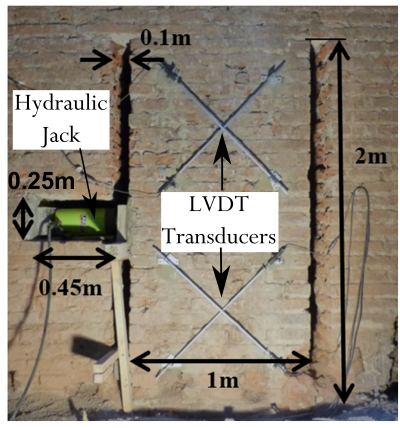

(a)

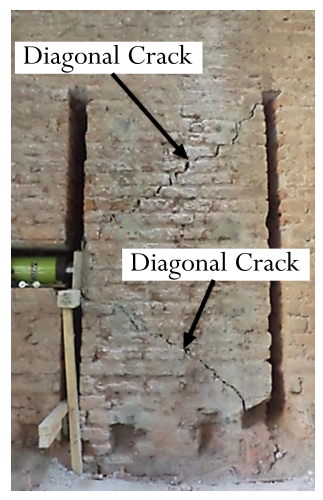

(b)

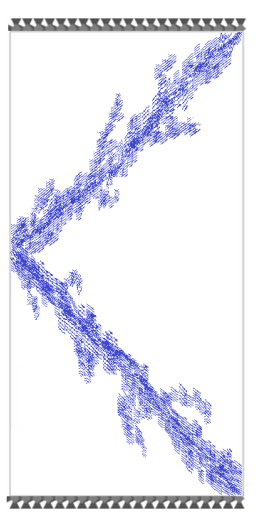

(c)

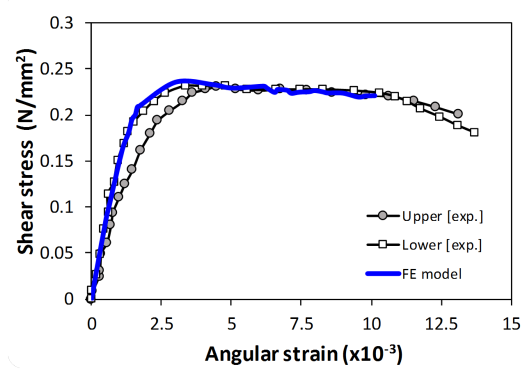

(d)

Figure 8: In situ shear test campaign to calibrate the material properties of the Palacio Pereira: (a) Shear compression test-setup, (b) post-test crack pattern of the experiment, (c) crack pattern of the FE analysis and (d) experimental and numerical stress-strain curves

Table 1: Material properties for the finite element model of the Palacio Pereira

\begin{tabular}{cccc}
\hline Material property & Symbol & Value & Unit \\
\hline Density & $\rho$ & 1800 & $\mathrm{~kg} / \mathrm{m}^{3}$ \\
Young's modulus & $E$ & 1.785 & $\mathrm{GPa}$ \\
$\begin{array}{c}\text { Poisson's ratio } \\
\text { Compressive strength }\end{array}$ & $f_{c}$ & 0.2 & - \\
$\quad \begin{array}{c}\text { Compressive } \\
\text { fracture energy }\end{array}$ & $G_{f c}$ & 15.7 & $\mathrm{kN} / \mathrm{m}$ \\
$\begin{array}{c}\text { Tensile strength } \\
\text { Tensile fracture }\end{array}$ & $f_{t}$ & 120 & $\mathrm{kN} / \mathrm{m}^{2}$ \\
$\begin{array}{c}\text { energy } \\
\text { Residual compressive }\end{array}$ & $G_{f}^{I}$ & 0.01 & $\mathrm{kN} / \mathrm{m}$ \\
$\quad$ strength & $f_{c, \text { res }}$ & 900 & $\mathrm{kN} / \mathrm{m}^{2}$ \\
Residual tensile & & & \\
strength & $f_{t, \text { res }}$ & 20 & $\mathrm{kN} / \mathrm{m}^{2}$ \\
\hline
\end{tabular}

shortening and lengthening in each specimen. Figure $8 \mathrm{~b}$ shows the experimental cracking pattern obtained after the test, with two diagonal cracks going through the two specimens. The in-situ shear test provided a shear strength $\tau_{\max }=0.23 \mathrm{MPa}$ for the existing masonry. Figure $8 \mathrm{~d}$ shows the shear stress vs. angular strain response for the two specimens. The observed experimental behavior was simulated numerically by means of a FE analysis of the in-situ experimental test. Conventional values were assumed for density and Poisson's ratio in the FE model, whereas the compressive strength of 2.1 MPa was defined in accordance with the standard ASCE 41-06 [48] for poor masonry. The remaining FE model parameters in Table 1 were evaluated in order to ob- tain a good agreement with the experimental evidence in terms of cracking pattern and stress-strain responses, see Figures 8c and 8d.

\subsection{Linear Seismic Analysis \\ 3.3.1. Modal Analysis}

The modal analysis of the Palacio Pereira is performed to obtain the modal shapes, their eigenfrequencies and participating masses. Figure 9 shows the trend of variation of the cumulative effective mass at each direction with the increasing number of modes of vibration. For the $\mathrm{x}$ - and $\mathrm{y}$-directions, a value around $70 \%$ seems to be the maximum value that can be reached after considering 500 eigenmodes. This result suggests to combine 500 modes in the response spectrum analysis to get the most accurate results.

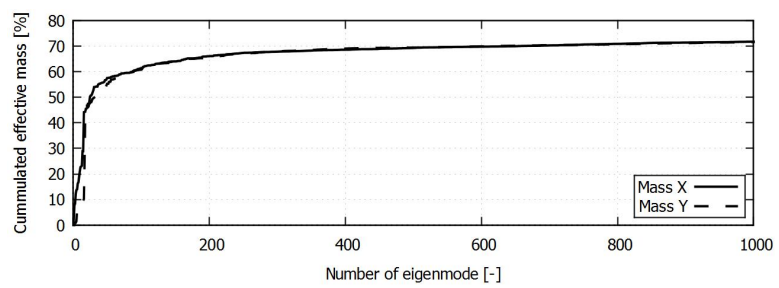

Figure 9: Modal analysis: cumulative effective mass from the eigenvalue analysis depending on the number of eigenmodes

Table 2 shows the most important vibration modes derived from the eigenvalue analysis, i.e. those with effective mass participation higher than $4 \%$.

Figure 10 and 11 show that the vibration modes reported in Table 2 are local ones and involve just small percentage of the mass of the whole structure. This 
Table 2: Main vibration modes of the Palacio Pereira

\begin{tabular}{|c|c|c|c|c|}
\hline & $\begin{array}{c}\text { Mode } \\
\text { number } \\
{[-]}\end{array}$ & $\begin{array}{c}\text { Period } \\
{[s]}\end{array}$ & $\begin{array}{c}\text { Frequency } \\
{[\mathrm{Hz}]}\end{array}$ & $\begin{array}{c}\text { Effective } \\
\text { mass } \\
{[\%]}\end{array}$ \\
\hline \multirow{3}{*}{$\mathbf{X}$} & 2 & 0.267 & 3.75 & 6.61 \\
\hline & 14 & 0.177 & 5.66 & 5.69 \\
\hline & 16 & 0.170 & 5.87 & 15.23 \\
\hline \multirow{3}{*}{$\mathbf{Y}$} & 6 & 0.238 & 4.20 & 4.22 \\
\hline & 17 & 0.161 & 6.21 & 14.40 \\
\hline & 18 & 0.156 & 6.40 & 18.28 \\
\hline
\end{tabular}

result is typical in irregular masonry buildings without box behavior.

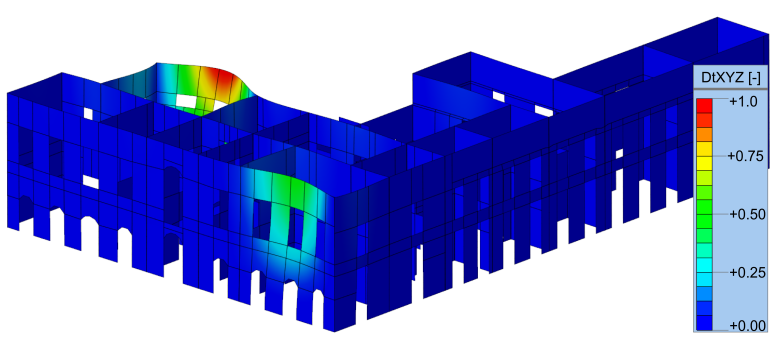

(a) Mode 2

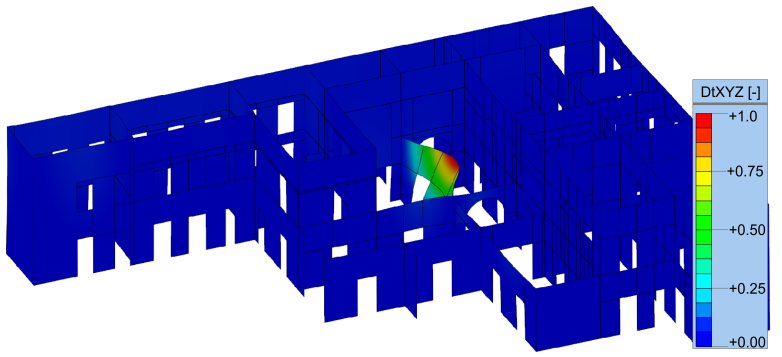

(b) Mode 14

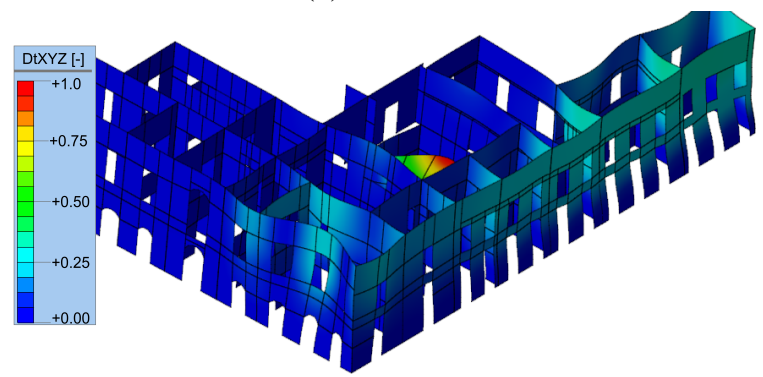

(c) Mode 16

Figure 10: Normalized mode shapes with mass participation higher than $5 \%$ in the $\mathrm{x}$-direction

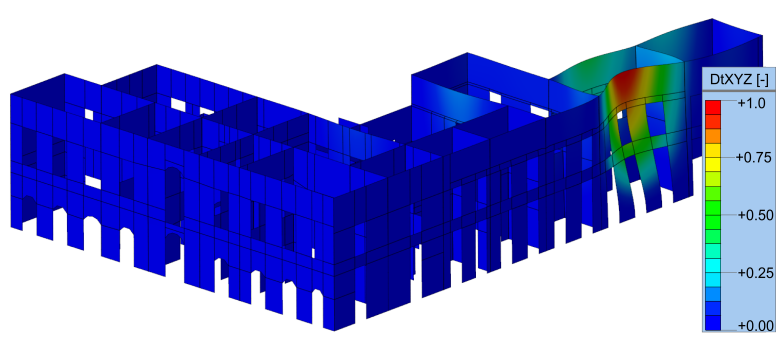

(a) Mode 6

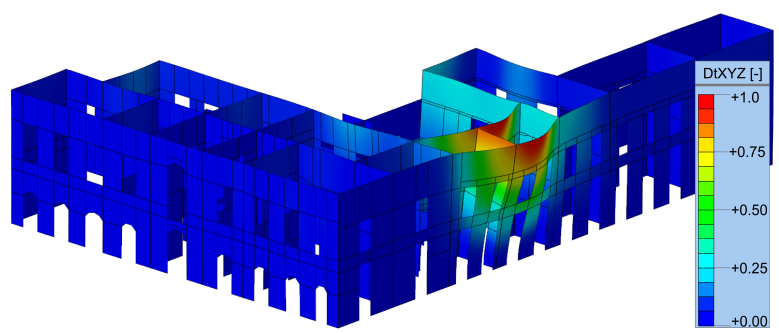

(b) Mode 17

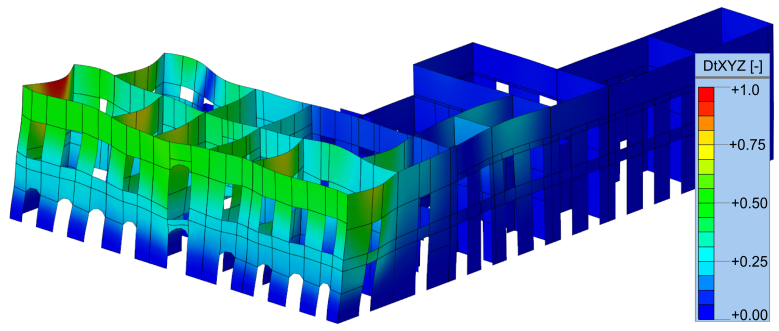

(c) Mode 18

Figure 11: Normalized mode shapes with mass participation higher than $4 \%$ in the y-direction

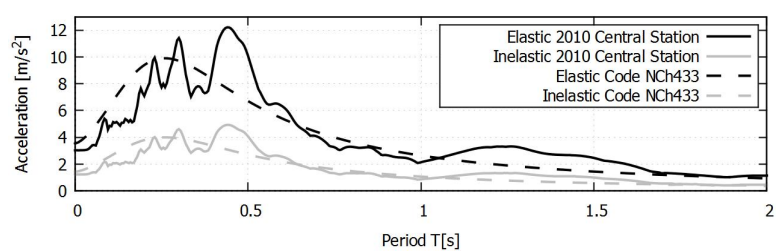

(a) Component in $\mathrm{x}$ direction

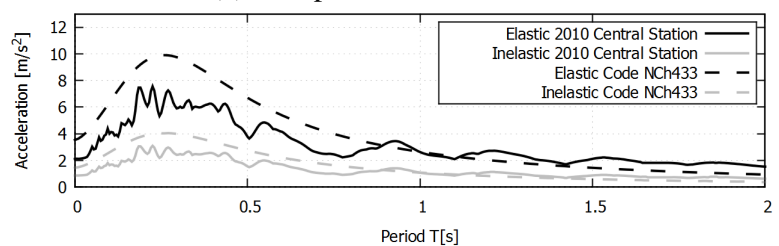

(b) Component in y direction

Figure 12: Acceleration spectra considered in the seismic assessment of the Palacio Pereira 


\subsubsection{Response spectrum analysis}

The response spectrum analysis (RSA) of the Palacio Pereira is performed by using four different spectra, shown in Figure 12. The elastic spectra of the 2010 earthquake are the same used by Sandoval et al. [37, 49]. The other two spectra are calculated following the Chilean standards NCh433 [50] for a building with a soil type III and a maximum ground acceleration $A_{0}=0.3 \mathrm{~g}$, according to the location of the building.

The reduction factor $R^{*}$, suggested by the Chilean standards for the reduction of the elastic spectra in the RSA, is calculated as follows:

$$
R^{*}=1+\frac{T^{*}}{0.1 T_{0}+\frac{T^{*}}{R_{0}}}
$$

where $T^{*}$ is the vibration period with the highest translational mass in the direction of the analysis, $T_{0}$

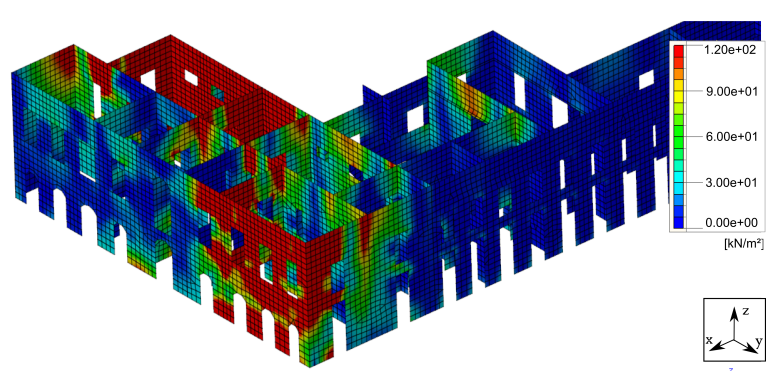

(a) Mode 2

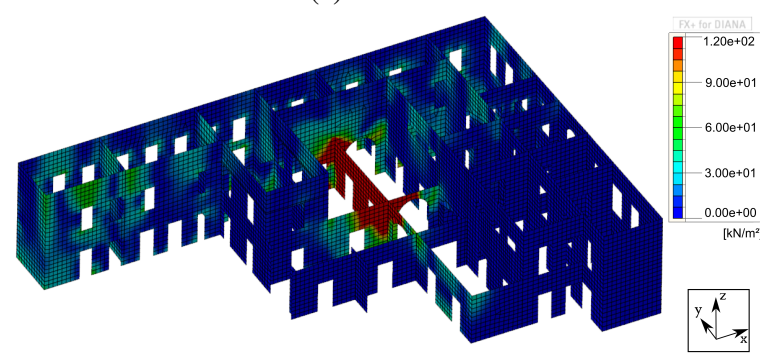

(b) Mode 14

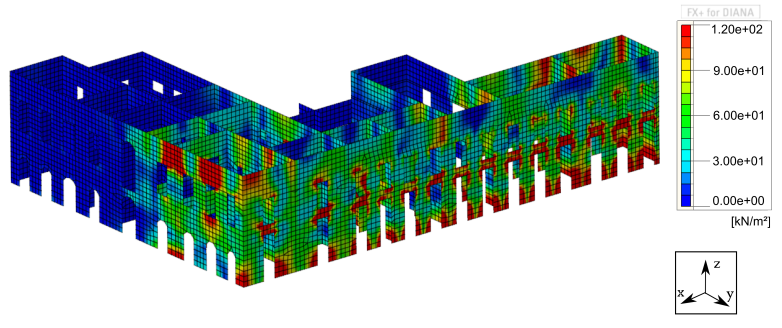

(c) Mode 16

Figure 13: Response spectrum analysis with inelastic spectra of 2010 earthquake: principal stress contours for major vibration modes in the $\mathrm{x}$-direction. is a parameter depending on the foundation soil, $R_{0}$ is the factor of modification of the response according to the structural typology. Since the RSA is executed along the two perpendicular directions $\mathrm{x}$ and $\mathrm{y}$, two different reduction factors are calculated. The parameter $T^{*}=0.170 \mathrm{~s}$ in the $\mathrm{x}$ direction, and $T^{*}=0.156 \mathrm{~s}$ in the y direction, being the modes 16 and 18 those with the highest translational masses in the two directions of the analysis, see Table 2 . The parameter $T_{0}=0.3$ for a type II soil, and $R_{0}=2$ for unreinforced masonry buildings. Therefore, the reduction factors $R^{*}=2.48$ in the $\mathrm{x}$ direction and $R^{*}=2.44$ in the y direction.

The inelastic spectra of the 2010 earthquake record is evaluated by using the same reduction factors $R^{*}$. Two different combination rules, the SRSS and the CQC, are

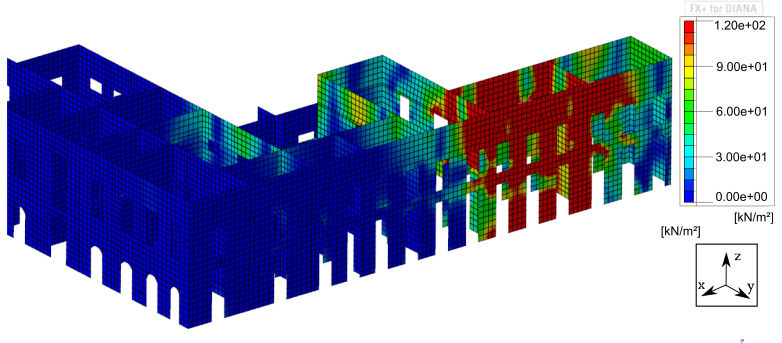

(a) Mode 6

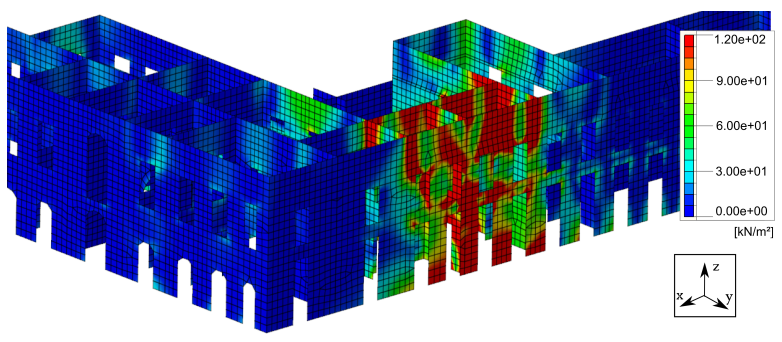

(b) Mode 17

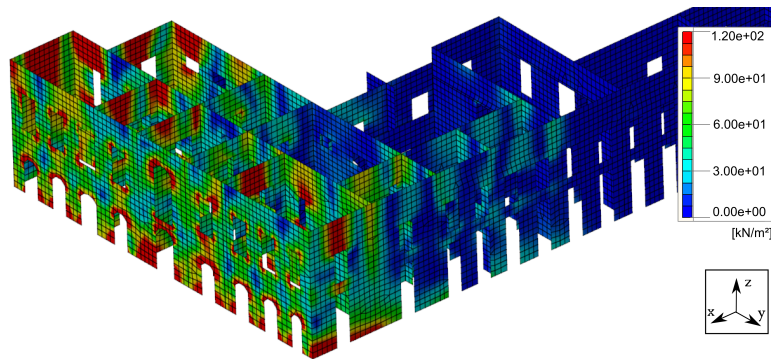

(c) Mode 18

Figure 14: Response spectrum analysis with inelastic spectra of 2010 earthquake: principal stress contours for major vibration modes in the y-direction. 
adopted. As mentioned in Section 3.3.1, 500 eigenmodes are considered.

Figures 13 and 14 show the principal stress contours for major modes in the x-direction $(2,14,16)$ and in the y-direction $(6,17,18)$ derived from the RSA with the 2010 earthquake inelastic spectra. The red contour indicates the regions in the building where the tensile principal stress exceeds the tensile strength of the material of $0.12 \mathrm{MPa}$. These regions may be interpreted as cracks corresponding to the activation of local outof-plane mechanisms (modes 2, 14, 6, 17), and in-plane failures in the east facade (mode 16) and south facade (mode 18).

\subsection{Nonlinear Seismic Analysis}

\subsubsection{Multi Directional Pushover Analysis}

The NSAs are carried out by considering a mass proportional distribution of horizontal forces. First, the pushover analyses are run along the four typical directions assumed in conventional NSA of regular buildings: positive transversal $\left(P_{0}\right)$, negative transversal $\left(P_{180}\right)$, positive longitudinal $\left(P_{90}\right)$ and negative longitudinal $\left(P_{270}\right)$. Second, supplementary NSAs are run along additional directions, according to the proposed MDPA approach, with the purpose of activating all the possible local collapse mechanisms around the building. The four additional pushover loading directions are $P_{45}, P_{135}, P_{225}$ and $P_{315}$. Figure 15 shows the eight pushover directions considered in the MDPA of the Palacio Pereira.

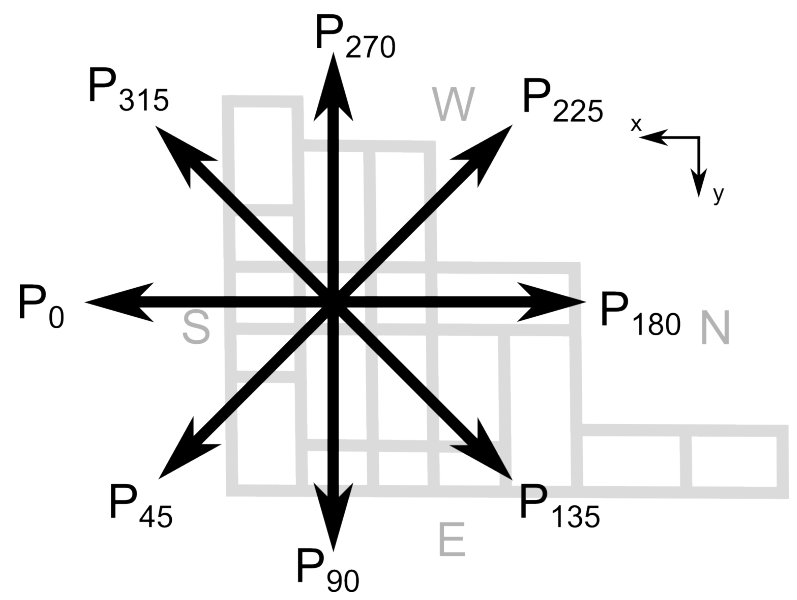

Figure 15: Loading directions assumed in the proposed multi directional pushover analysis of the Palacio Pereira.

Each NSA is carried out by considering a two-step procedure. In the first stage, the gravitational loading is applied to the model. In the second stage, the structure is horizontally pushed by a mass proportional horizontal loading pattern. The nonlinear numerical problem is solved by using an arc-length control and NewtonRaphson method.

Figure 16 shows the control nodes for NSA and NDA that have been chosen according to the collapse mechanisms observed in the eight pushover analyses. Large out-of-plane displacements occur in the walls during the MDPA, thus the control nodes are placed at their top.

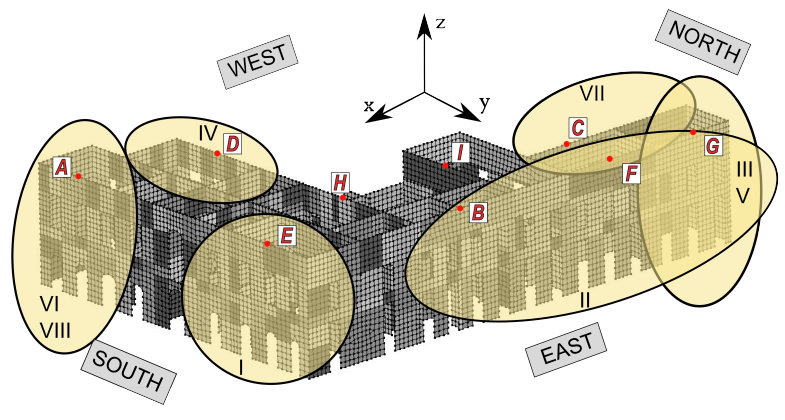

Figure 16: Overview of the locations of the failure mechanisms detected during the multi directional pushover analysis, and positions of the considered control nodes.

Table 3 shows the ultimate out-of-plane displacement values $d_{u}$ of the chosen control nodes, and the maximum accelerations $a_{\max }$ derived from the eight MDPAs. The maximum acceleration values range between 0.154 $g$ and $0.234 g$.

Table 3: Maximum acceleration values derived from each pushover analysis and ultimate displacements of the control nodes in $\mathrm{x}$ - or $\mathrm{y}$ direction. Seismic performance in terms of displacements and accelerations and transformation factors from MDOF to SDOF according to the N2 method

\begin{tabular}{ll|lc|ccc} 
& & \multicolumn{3}{c}{ Peak values } & \multicolumn{3}{c}{ N2-method } \\
\hline & $\begin{array}{c}\text { node } \\
\text { (dir.) }\end{array}$ & $\begin{array}{c}a_{\max } \\
{[\mathrm{g}]}\end{array}$ & $\begin{array}{c}d_{u} \\
{[\mathrm{~m}]}\end{array}$ & $\begin{array}{c}\Gamma \\
{[-]}\end{array}$ & $\begin{array}{c}d_{p p} \\
{[\mathrm{~cm}]}\end{array}$ & $\begin{array}{c}a_{p p} \\
{[\mathrm{~g}]}\end{array}$ \\
\hline$P_{0}$ & $\mathrm{E}(\mathrm{x})$ & 0.193 & 0.254 & 2.68 & 6.69 & 0.177 \\
$P_{45}$ & $\mathrm{E}(\mathrm{x})$ & 0.154 & 0.048 & 2.66 & 3.99 & 0.148 \\
$P_{90}$ & $\mathrm{G}(\mathrm{y})$ & 0.216 & 0.116 & 3.16 & 2.68 & 0.167 \\
$P_{135}$ & $\mathrm{G}(\mathrm{y})$ & 0.176 & 0.071 & 3.44 & 4.69 & 0.171 \\
$P_{180}$ & $\mathrm{D}(\mathrm{x})$ & 0.234 & 0.042 & 2.68 & 4.11 & 0.233 \\
$P_{225}$ & $\mathrm{~A}(\mathrm{x})$ & 0.192 & 0.048 & 2.66 & 4.44 & 0.191 \\
$P_{225}$ & $\mathrm{D}(\mathrm{x})$ & 0.192 & 0.062 & 2.66 & 5.24 & 0.189 \\
$P_{225}$ & $\mathrm{G}(\mathrm{y})$ & 0.192 & 0.042 & 2.81 & 2.92 & 0.182 \\
$P_{270}$ & $\mathrm{C}(\mathrm{y})$ & 0.225 & 0.292 & 3.16 & 2.92 & 0.176 \\
$P_{315}$ & $\mathrm{~A}(\mathrm{x})$ & 0.170 & 0.078 & 2.69 & 7.31 & 0.169 \\
\hline
\end{tabular}

The elastic design spectra of the Chilean standards NCh433 (Figure 12) is used to evaluate the structural response at the performance point (PP). The PP is deter- 
mined by considering the procedure presented in Section 2.2.2. Table 3 shows the transformation factor $\Gamma$, the acceleration $a_{p p}$ and displacement $d_{p p}$ at the performance point for the MDOF system corresponding to each NSA. As previously mentioned in Section 2.2.2, different transformation factors are calculated for different NSA loading orientations. Table 3 indicates the direction considered for their calculation (X or $\mathrm{Y}$ ) for each pushover direction, according to the control displacement chosen to describe the obtained partial collapse mechanisms. It is worth noticing that NSA $P_{225}$ is able to activate overturning mechanisms in three different walls and for this reason the results are detailed for the three cases (control nodes A, D and G).

The determination of the local failure mechanisms through the MDPA of the Palacio Pereira is carried out by considering the progressive damage appearing during each NSA. Figure 16 shows the locations of all the failure mechanisms detected during the eight pushover analyses. As shown, the seismic response of the building is characterized by partial mechanisms, as expected in an irregular masonry building without box behavior. Figure 17 shows the total displacement contours at the PP for each pushover analysis. Figure 18 shows the capacity curves of each NSA for the out-of-plane displacement of the relevant control nodes. The description of each failure mechanism derived from MDPA is presented in detail in the following.

- Pushover $\boldsymbol{P}_{\mathbf{0}}$ The mechanism in $P_{0}$ is an out of plane failure of the eastern part of the south facade along the positive $\mathrm{x}$-direction. The global displacements at the PP are shown in Figure 17a. The first plateau of the capacity curve with control node $\mathbf{E}$ of Figure $18 \mathrm{a}$ is produced by the cracks developing in the spandrels of the walls perpendicular to the overturning part of the south facade. Increasing lateral acceleration leads to large displacements of the wall and finally to out of plane collapse of the eastern part of the south facade. This failure is designated as Mechanism I.

- Pushover $\boldsymbol{P}_{45}$ The lateral acceleration activates the same failure observed in $P_{0}$, i.e. the Mechanism I. Figure $17 \mathrm{~b}$ shows the global displacements of the structure at the PP. As in $P_{0}$, the lateral acceleration induces first the development of cracks in the spandrels of the wall transversal to the east portion of the south facade. This behavior can be detected by analyzing the capacity curve of control node $\mathbf{E}$ shown in Figure 18b. At an acceleration of approximately $0.12 \mathrm{~g}$, the slope of the capacity curve flattens and then the increasing acceleration leads to the out of plane collapse.

- Pushover $\boldsymbol{P}_{\mathbf{9 0}}$ A further rotation of $45^{\circ}$ of the pushover angle activates a different mechanism than the previous one displayed by $P_{0}$ and $P_{45}$. The lateral acceleration leads to the out of plane failure of a big portion of the east facade along the positive y-direction (Mechanism II). Figure 17c shows the global displacements of $P_{90}$ at the PP. Figure 18c presents the capacity curve of control node $\mathbf{G}$. At an acceleration of approximately $0.18 g$ the wall perpendicular to the east facade at location of control node B undergoes shear cracking. This causes a sudden drop of the structural capacity. Further cracks appear in the walls perpendicular to the east facade while increasing the acceleration, until reaching the overturning of the facade.

- Pushover $\boldsymbol{P}_{135}$ Figure $17 \mathrm{~d}$ shows the global displacements of $P_{135}$ at the PP, and depicts an out of plane failure of only the northern part of the east facade in positive y-direction (Mechanism III). Figure $18 \mathrm{~d}$ shows the capacity curve of control node $\mathbf{G}$. The first drop of stiffness of the capacity curve is caused by cracks in the spandrels of the facade. Further increase of the load results in cracks at the perpendicularly connected walls which activate the collapse.

- Pushover $\boldsymbol{P}_{180}$ Figure $17 \mathrm{e}$ shows the global displacements at the PP for Mechanism IV, that is the out of plane failure along the negative $\mathrm{x}$-direction of the western part of the wall overlooking the courtyard parallel to the south facade. Figure 18e shows the capacity curve of $P_{180}$ with the corresponding control node D. Cracks in one perpendicular wall cause a first change of stiffness at $0.11 \mathrm{~g}$ lateral acceleration. A sudden drop of capacity occurs at $0.18 \mathrm{~g}$ due to cracks in the corner and at the connection of the walls. The cracks grow further and lead to the out of plane failure at control node $\mathbf{D}$.

- Pushover $\boldsymbol{P}_{225}$ Figure $17 \mathrm{f}$ shows that the NSA along this direction activates several mechanisms. First, there is the out of plane failure at node D which has already been introduced as Mechanism IV. This mechanism leads to total collapse of the FE model. However, two further large displacements of walls can be detected, such as the out of plane displacements in negative $\mathrm{x}$-direction of the western part of the south facade at node A (Mechanism V). Further large displacements occur at the northern part of the east facade in negative y-direction and activate Mechanism VI. Figure 18f, $18 \mathrm{~g}$ and $18 \mathrm{~h}$ show 


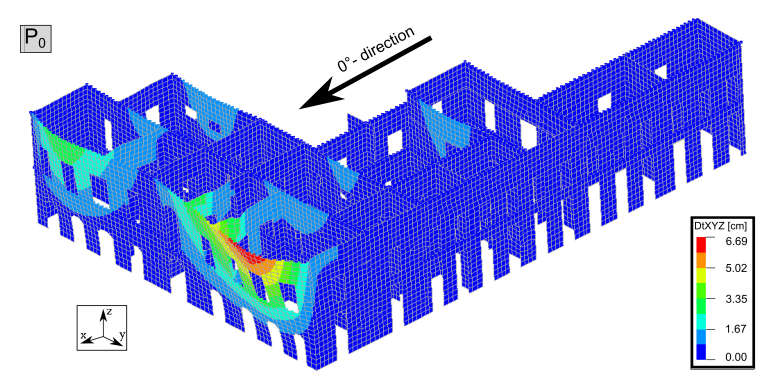

(a) of $P_{0}$

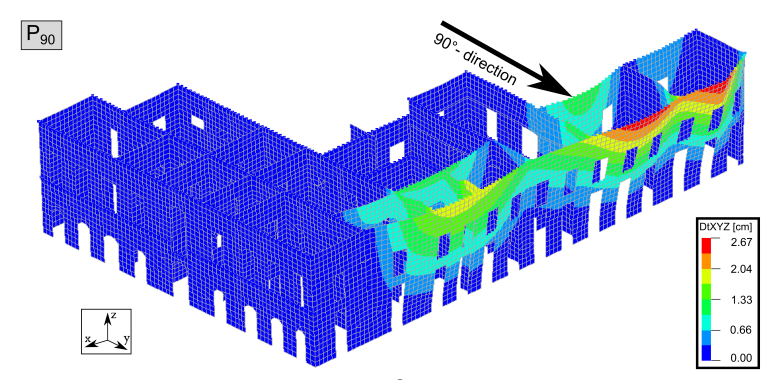

(c) of $P_{90}$

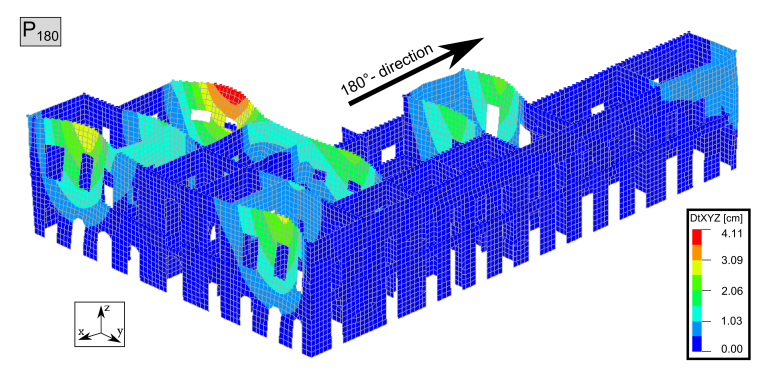

(e) of $P_{180}$

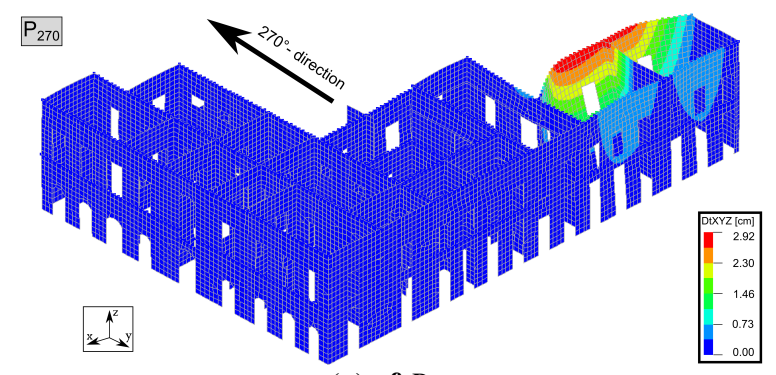

(g) of $P_{270}$

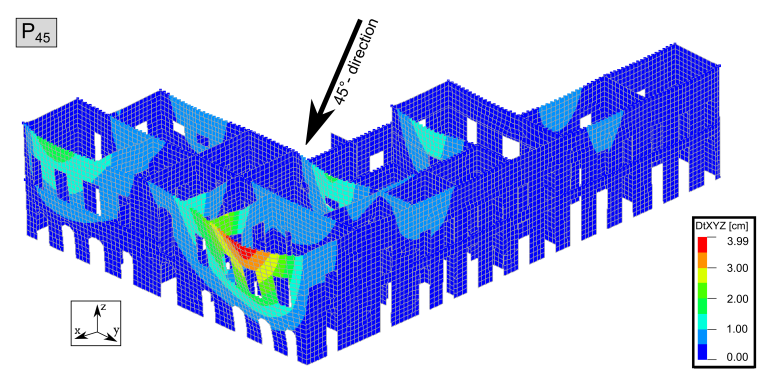

(b) of $P_{45}$

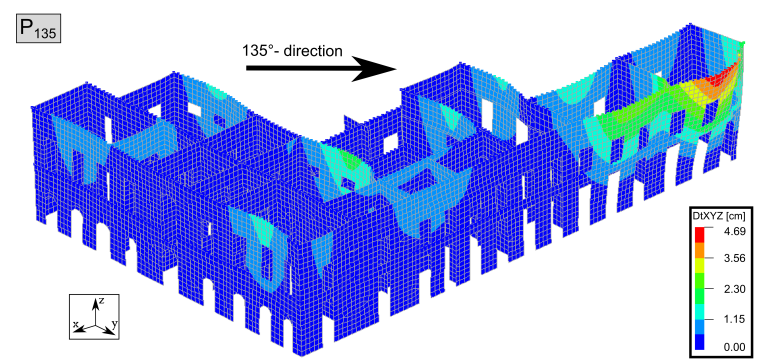

(d) of $P_{135}$

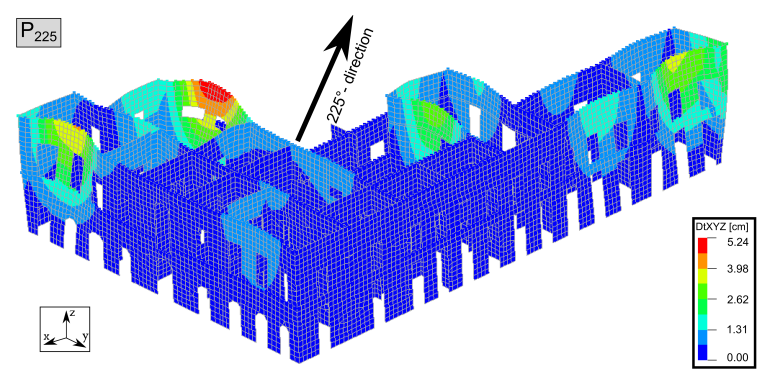

(f) of $P_{225}$

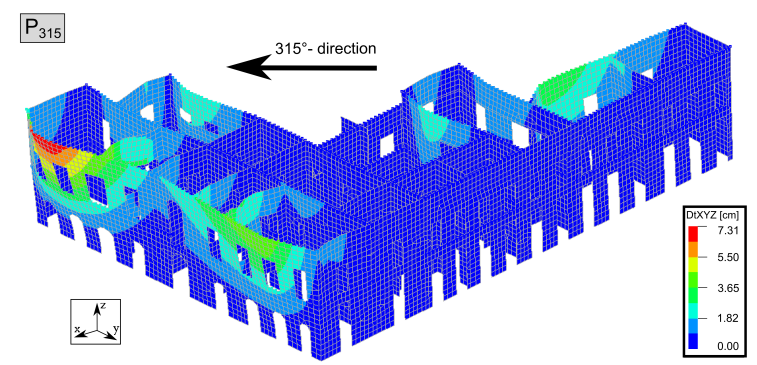

(h) of $P_{315}$

Figure 17: Global displacements at the performance point for all the individual nonlinear static analyses of the proposed multi directional pushover approach

the capacity curves of the three nodes corresponding to the mechanisms. Large cracks at the connection to the perpendicular walls appear in Mechanism IV. Cracks in the spandrels of the perpendicular wall of Mechanism VI decrease the stiffness and the connection of the east facade cracks in Mechanism VI.
- Pushover $\boldsymbol{P}_{\mathbf{2 7 0}}$ The pushover analysis along this direction activates Mechanism VII. Figure $17 \mathrm{~g}$ shows large out of plane diplacements at the inner wall parallel to the east facade at node $\mathbf{C}$. Figure $18 \mathrm{i}$ shows the capacity curve of control node $\mathbf{C}$ during $P_{270}$ and demonstrates the beginning of the nonlinear range at 


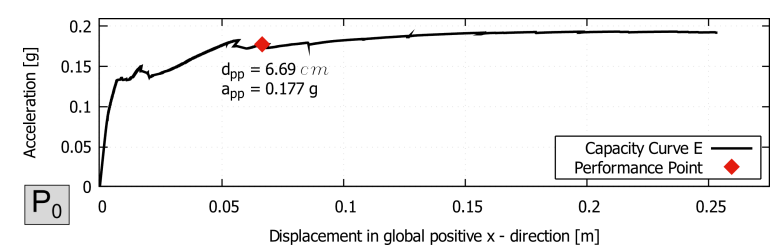

(a) Mechanism I: $P_{0}$ - node $\mathrm{E}$

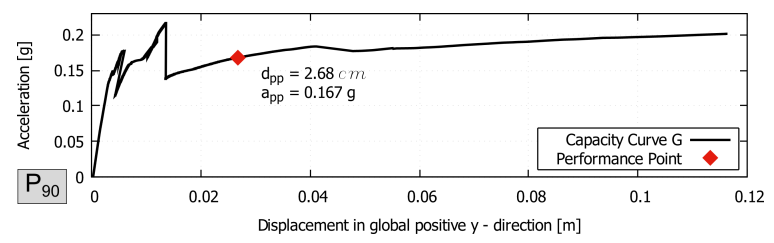

(c) Mechanism II: $P_{90}$ - node G

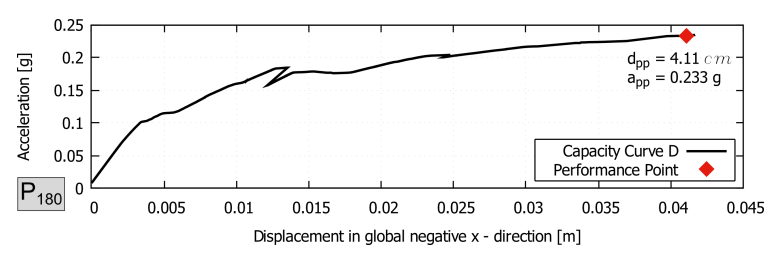

(e) Mechanism IV: $P_{180}$ - node D

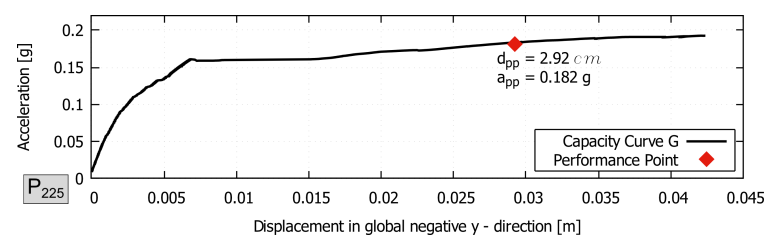

(g) Mechanism V: $P_{225}$ - node G

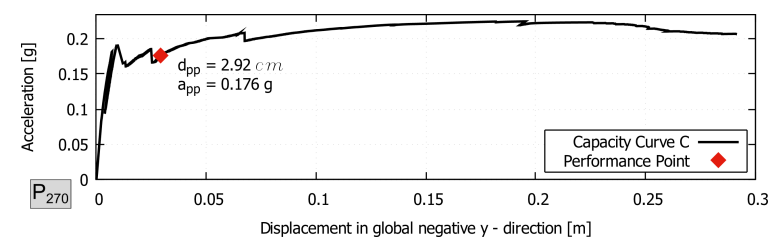

(i) Mechanism VII: $P_{270}-$ node C

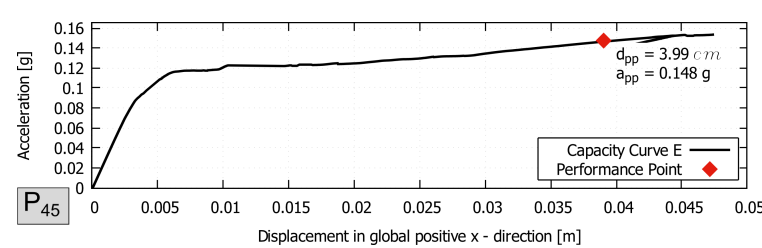

(b) Mechanism I: $P_{45}-$ node E

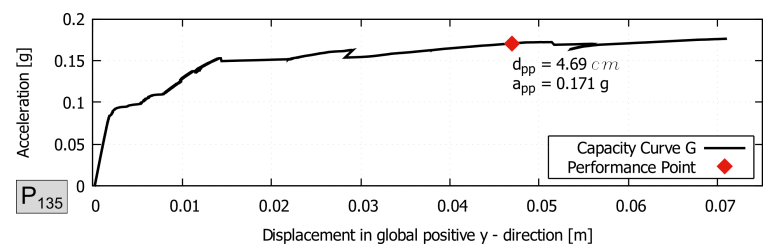

(d) Mechanism III: $P_{135}$ - node G

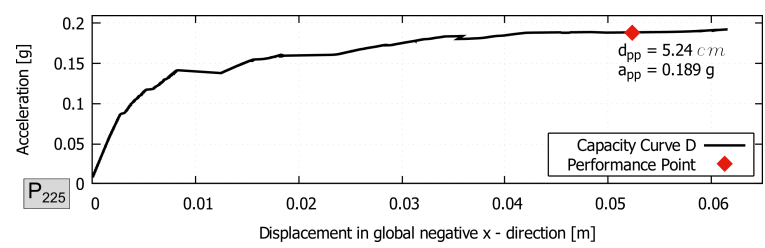

(f) Mechanism IV: $P_{225}-$ node D

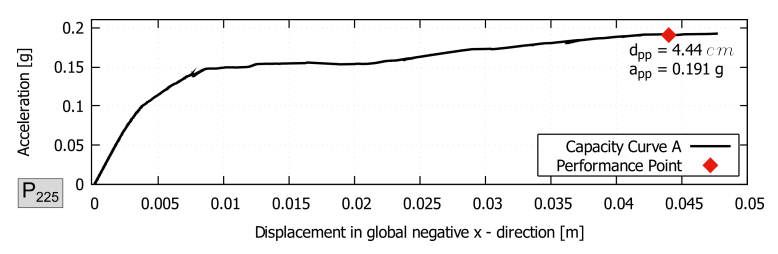

(h) Mechanism VI: $P_{225}-$ node A

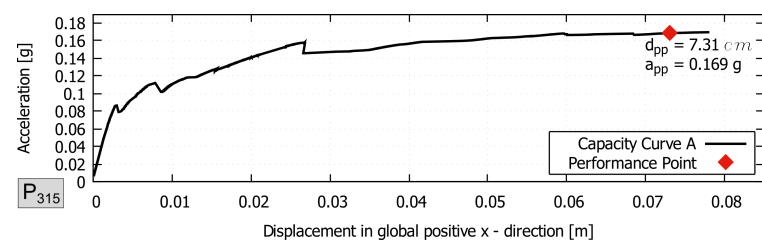

(j) Mechanism VIII: $P_{315}$ - node A

Figure 18: Capacity curves and evaluation of the performance point for all the individual nonlinear static analyses of the proposed multi directional pushover approach

a lateral acceleration value of approximately $0.19 \mathrm{~g}$. This loading leads to large cracks in the connection to the perpendicular wall. Further increase of the lateral acceleration loads activate the out of plane collapse until total failure of the wall.

- Pushover $\boldsymbol{P}_{\mathbf{3 1 5}}$ Figure $17 \mathrm{~h}$ shows large deformations occurring at the most western part of the south facade. Figure $18 \mathrm{j}$ shows the capacity curve of the corresponding control node $\mathbf{A}$. The formation of cracks in the lower spandrel of the perpendicular wall initiates the drop of capacity at around $0.09 \mathrm{~g}$. At ap- proximately $0.11 \mathrm{~g}$ the crack in the upper spandrel of the same wall becomes larger and causes further yielding. Increase of the lateral acceleration leads to growing cracks. Finally, Mechanism VIII is activated and the wall fails out of plane.

Table 4 shows the maximum displacements of the control nodes A, C, D, E and G in x- and y-direction, respectively. Next Section 3.4.2 presents a careful comparison of their values with those derived from NDA. 
Table 4: Comparison among the maximum displacements derived from the nonlinear dynamic analyses (NDA), the performance displacements of the pushover analyses (NSA) and the maximum displacement obtained from the response spectrum analysis (RSA) with inelastic design spectra. Calculation of relative errors of NSA and RSA displacements compared with NDA displacements.

\begin{tabular}{|c|c|c|c|c|c|c|c|c|}
\hline & & \multicolumn{2}{|c|}{ NDA } & \multicolumn{3}{|c|}{ NSA (PP) } & \multicolumn{2}{|c|}{ RSA } \\
\hline Control Node & Direction & $\begin{array}{c}t \\
{[\mathrm{~s}]}\end{array}$ & $\begin{array}{c}d_{\max } \\
{[\mathrm{cm}]}\end{array}$ & $I d$ & $\begin{array}{c}d_{p p} \\
{[\mathrm{~cm}]}\end{array}$ & $\begin{array}{c}\chi_{N S A} \\
{[\%]}\end{array}$ & $\begin{array}{c}d_{\max } \\
{[\mathrm{cm}]}\end{array}$ & $\begin{array}{l}\chi_{R S A} \\
{[\%]}\end{array}$ \\
\hline \multirow{2}{*}{ A } & \multirow{2}{*}{$\mathrm{x}$} & 29.10 & 7.45 & $P_{315}$ & 7.31 & 1.9 & 4.09 & 45.1 \\
\hline & & 28.20 & -6.65 & $P_{225}$ & -4.44 & 33.2 & -4.13 & 37.9 \\
\hline \multirow{2}{*}{$\mathrm{C}$} & \multirow[b]{2}{*}{$\mathrm{y}$} & 29.54 & 2.90 & - & - & - & 2.78 & 4.3 \\
\hline & & 19.71 & -2.81 & $P_{270}$ & -2.92 & 3.91 & -2.74 & 2.5 \\
\hline \multirow{2}{*}{$\mathrm{D}$} & \multirow{2}{*}{$\mathrm{x}$} & 29.06 & 5.51 & - & - & - & 4.36 & 20.8 \\
\hline & & 28.20 & -9.45 & $P_{225}$ & -5.24 & 44.5 & -4.18 & 55.8 \\
\hline \multirow{2}{*}{$\mathrm{E}$} & \multirow[b]{2}{*}{$\mathrm{X}$} & 28.97 & 8.78 & $P_{0}$ & 6.69 & 23.8 & 4.93 & 43.8 \\
\hline & & 28.22 & -6.80 & - & - & - & -4.84 & 28.8 \\
\hline \multirow{2}{*}{ G } & \multirow[b]{2}{*}{$\mathrm{y}$} & 29.51 & 4.75 & $P_{135}$ & 4.69 & 1.26 & 2.16 & 54.6 \\
\hline & & 28.17 & -3.06 & $P_{225}$ & -2.92 & 4.58 & -2.03 & 33.7 \\
\hline & & & & & $\bar{\chi}_{N S A}$ & 16.2 & $\bar{\chi}_{R S A}$ & 32.7 \\
\hline
\end{tabular}

\subsubsection{Nonlinear Dynamic Analysis}

This section presents the results of the NDA of the Palacio Pereira. The transient acceleration which acts on the FE model of the building is the time history of the 2010 earthquake recorded at the Santiago Central Station in the transversal and longitudinal directions, respectively. Figure 19 shows the most significant time frame of 80 seconds of the time history of the 2010 earthquake acceleration in longitudinal (y) and transversal (x) directions.

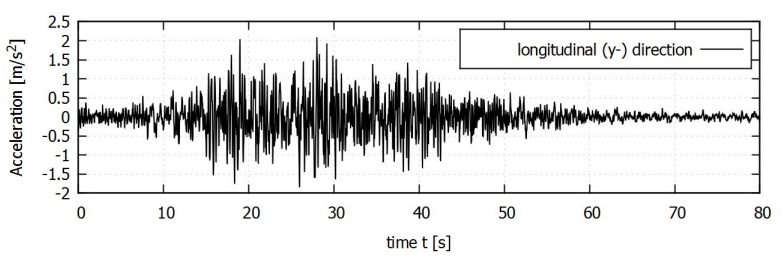

(a) Longitudinal ground acceleration

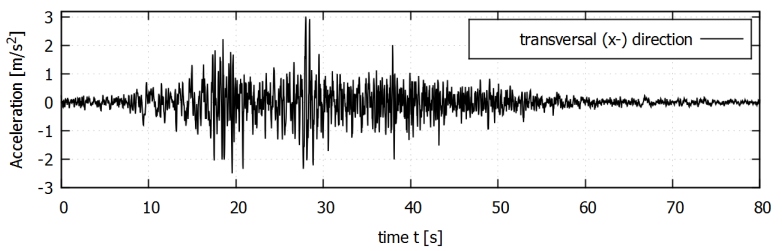

(b) Transversal ground acceleration

Figure 19: Time history of the 2010 earthquake longitudinal and transversal accelerations recorded at the Central Station of Santiago

The NDA is performed by letting both the $\mathrm{x}$ and $\mathrm{y}$ components acting simultaneously. The time integration method is the Newmark-beta with $\gamma=\frac{1}{2}$ and $\beta=\frac{1}{4}$.
An automatic time step actualization is used with maximum time step size $\Delta t_{\max }=0.025 \mathrm{~s}$ and minimum step size is $\Delta t_{\min }=1.0 \cdot 10^{-9}$. The maximum time step size is based on the criterion of $\Delta t=0.1 \cdot T_{1}$ suggested by Chopra [51], being $T_{1}=0.268 s$ the period of the first mode. However, since the contribution of the first mode is not predominant in this structure, as already discussed in Section 3.3.1, the automatic time step actualization has been controlled throughout all the analysis to ensure the proper accuracy of the results. The constitutive model is the total strain based crack model as for the NSA.

The classical Rayleigh damping matrix of type $C=$ $a_{0} M+a_{1} K$ is used in NDA. The definition of the coefficients $a_{0}$ and $a_{1}$ can be obtained by regarding the method presented by Chopra [51]. The range of the modes not overdamped ranges from mode 2 to mode 18 for the Palacio Pereira. Table 2 shows the corresponding eigenfrequencies. The coefficients for the implementation of the damping model are $a_{0}=0.2365 \mathrm{~s}^{-1}$ and $a_{1}=0.009852 \mathrm{~s}$. Figure 20 shows the obtained values for the damping ratios versus the frequency.

The NDA of the Palacio Pereira is performed until the end of the 80 seconds of the earthquake excitation. This is in agreement with the real behavior of the Palacio Pereira during the earthquake in 2010, because the collapse of the building did not occur, even though the structure was severely damaged.

Several initiating failure mechanisms can be detected by considering the analysis results. The results of the last step at 80 seconds show a significant amount of ac- 


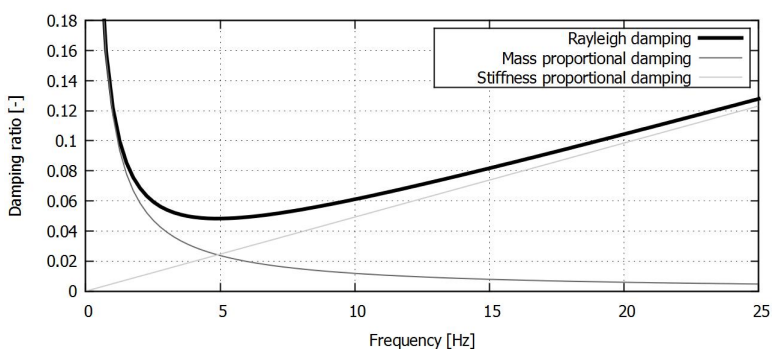

Figure 20: Rayleigh damping model

cumulated hysteretic damage on the building, and the activated failure mechanisms are not sufficient to interrupt the NDA. The entire set of results is analyzed to identify possible failure mechanisms, as reported in the next section. The maximum displacements of the NDA and the PPs of the NSA are compared by considering the same control nodes. Table 4 shows the maximum displacements of the control nodes A, C, D, E and G directly compared with the performance displacements from the MDPA. The overall maximum displacement during the NDA is reached by control node $\mathrm{D}$ in the negative $\mathrm{x}$-direction with a value of $9.45 \mathrm{~cm}$. Figure 21 shows the displacements in $\mathrm{x}$ direction at 28.20 seconds of the NDA, where the maximum displacement is reached.

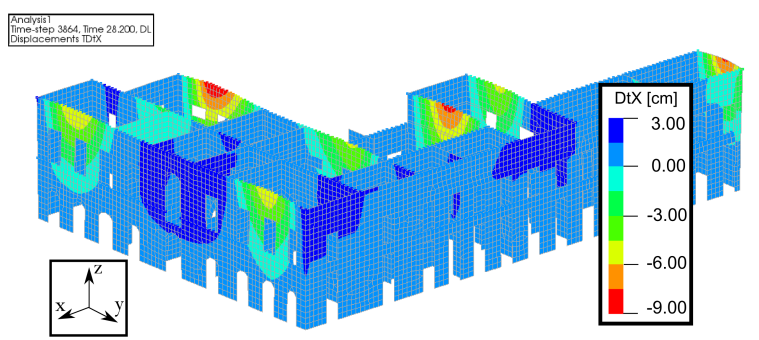

Figure 21: Contour plot of displacements in $\mathrm{x}$ direction provided by nonlinear dynamic analysis at 28.2 seconds.

Even though the base accelerations of the earthquake record reach similar maximum values in $\mathrm{x}$ and $\mathrm{y}$ directions, the displacements of the structure are bigger in $\mathrm{x}$ than in y-direction. This is due to the intrinsic irregularity of the building. A similar behavior is obtained by the PP of the NSA results, where the displacements in $\mathrm{x}$ direction are bigger than the ones in y-direction. Table 4 shows also the displacements of the RSA, with inelastic Chilean design spectra and CQC combination rule, after having amplified them with the reduction factor $R^{*}$ introduced in Section 3.3.2.

Table 4 shows the percentage relative errors of NSA and RSA displacements compared with the NDA refer- ence values, for the different control nodes and along both positive and negative directions. All these different relative errors are averaged for the NSA and the RSA. The mean relative error $\bar{\chi}_{N S A}$ of the MDPA results $16.2 \%$, showing a proper approximation of the MDPA results to the ones obtained by NDA. In addition, $\bar{\chi}_{N S A}$ results lower than the mean relative error $\bar{\chi}_{R S A}$ of $32.7 \%$ for the RSA. This important outcome shows the capability of the proposed MDPA to reproduce the overall seismic response of the irregular masonry building without box behavior.

\section{Discussion}

\subsection{Comparison between Multi Directional Pushover Analysis and Nonlinear Dynamic Analysis}

MDPA including eight pushover analyses provides useful information about various possible collapse mechanisms in the considered irregular structure without box behavior. The NDA, which considers simultaneously the two perpendicular time histories of the earthquake and accounts directly for nonlinear dynamic effects, can be compared with the overall results of the proposed MDPA. This kind of comparison is necessary in order to evaluate the capability of the MDPA to display all the damage and collapse mechanisms provided by the NDA and produced by the 2010 earthquake. The description of the failure mechanisms is based on the contour plots of crack width at meaningful steps of the analysis. Plots of each analysis are generated for both the MDPA at each PP and NDA at the step when the mechanism is clearly detectable. The smallest cracks plotted have a width of $1.0 \mathrm{~mm}$. Figures 22 and 23 show all the local failure mechanisms mentioned in Section 3.4.1. The similarities of the mechanisms obtained by NDA and MDPA are analyzed in the following.

Mechanism I (Figure 22a and 22b) shows very similar crack patterns for both NDA and $P_{0}$ NSA. The spandrels of the perpendicular walls are cracked and the mechanism is produced by the out of plane deformation in the positive $\mathrm{x}$ direction.

Mechanism II (Figure 22c and 22d) presents the entire out of plane overturning of the east facade of the Palacio Pereira. It is caused by vertical cracks in all the walls perpendicularly connected to the facade. Both the NDA and the $P_{90}$ NSA present this mechanism.

Mechanism III (Figure 22e and 22f) is identified by an out of plane overturning in positive $y$-direction of the east facade with control node G. Large cracks in the walls connected perpendicularly to the facade are correctly displayed by both NDA and $P_{135}$ NSA. Both the 


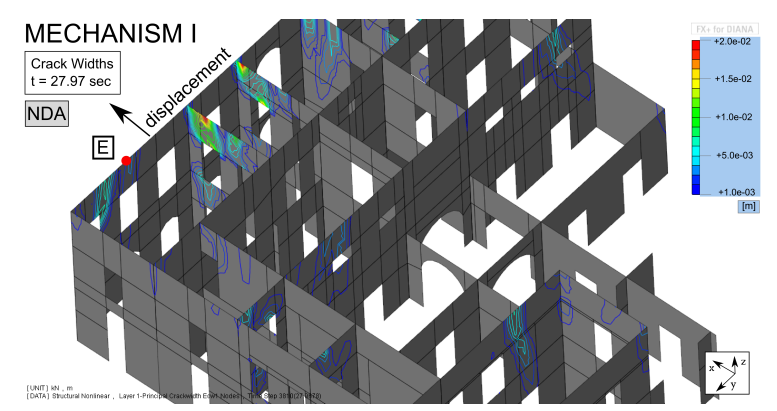

(a) NDA - mechanism I

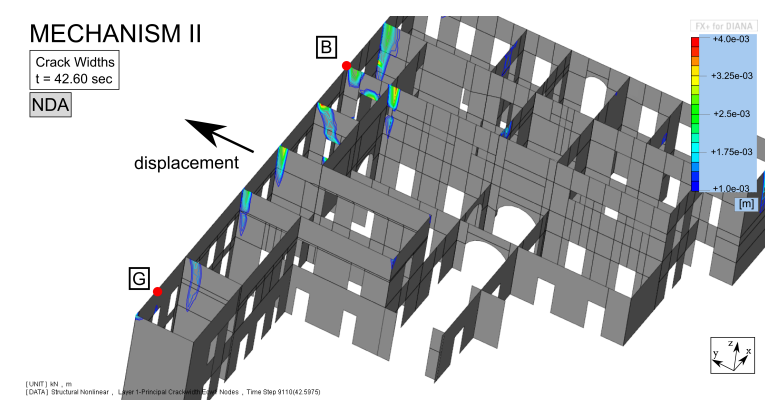

(c) NDA - mechanism II

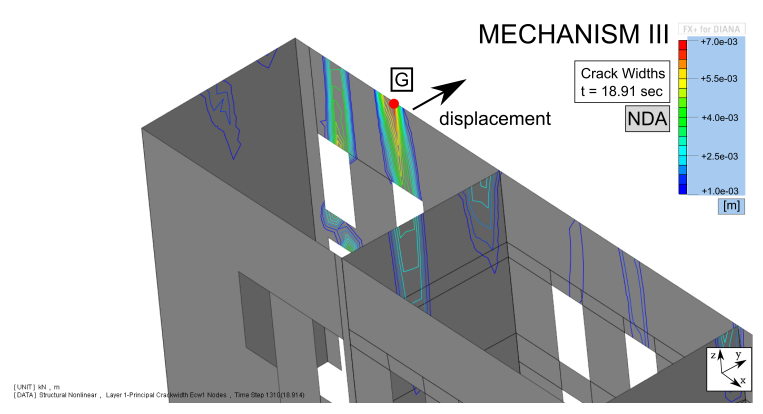

(e) NDA - mechanism III

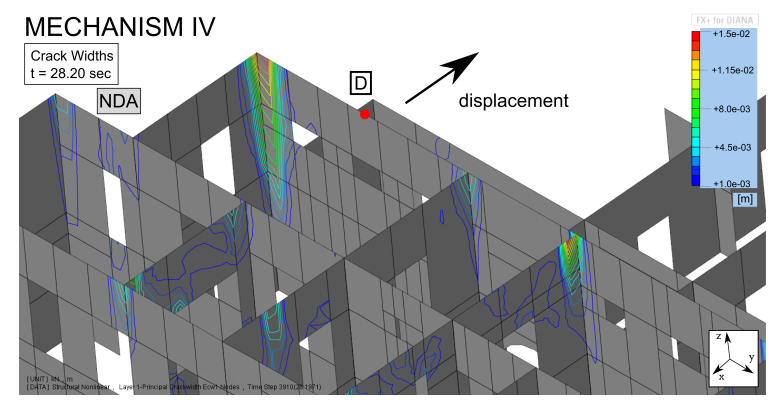

(g) NDA - mechanism IV

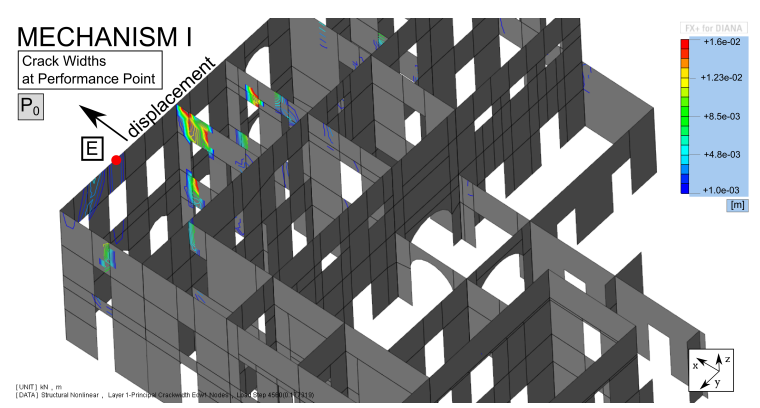

(b) NSA $\left(P_{0}\right)$ - mechanism I

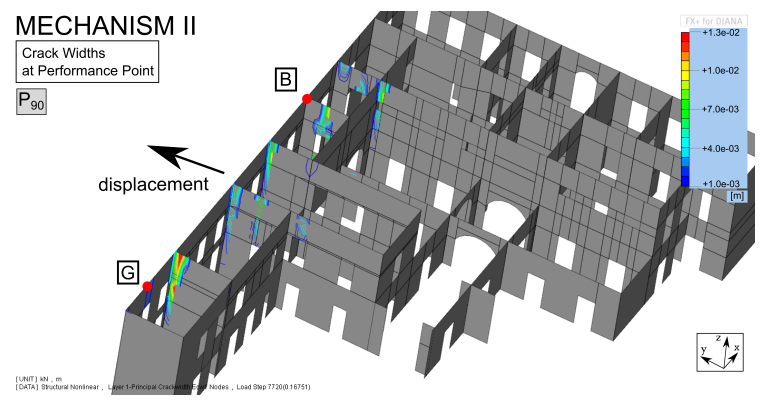

(d) NSA $\left(P_{90}\right)$ - mechanism II

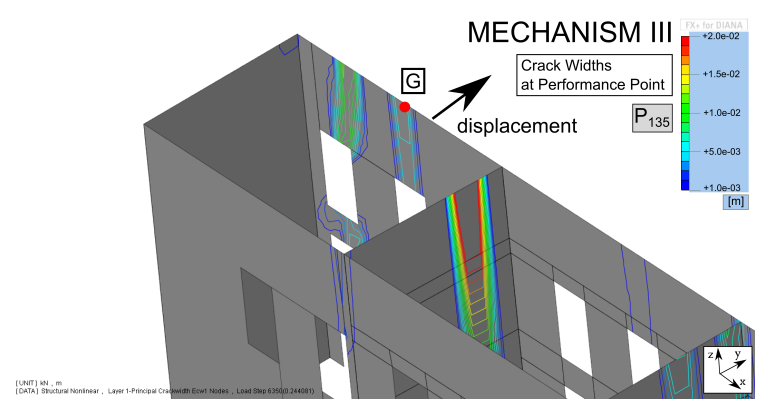

(f) NSA $\left(P_{135}\right)$ - mechanism III

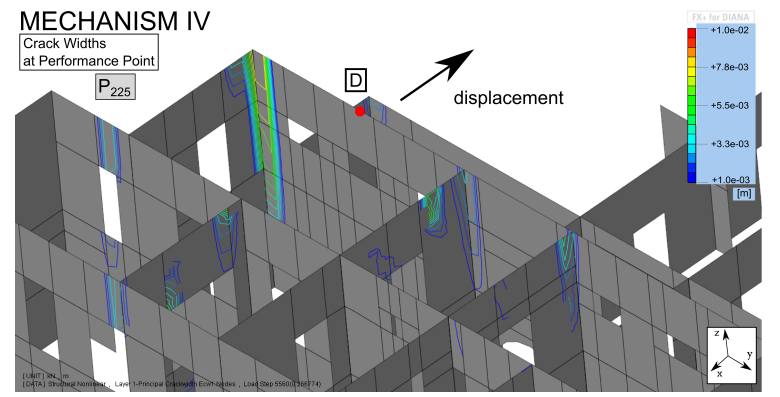

(h) NSA $\left(P_{225}\right)$ - mechanism IV

Figure 22: Contour plots of the crack width larger than $1.0 \mathrm{~mm}$ for mechanisms I to IV provided by the nonlinear dynamic and static analyses (NDA and NSA) 

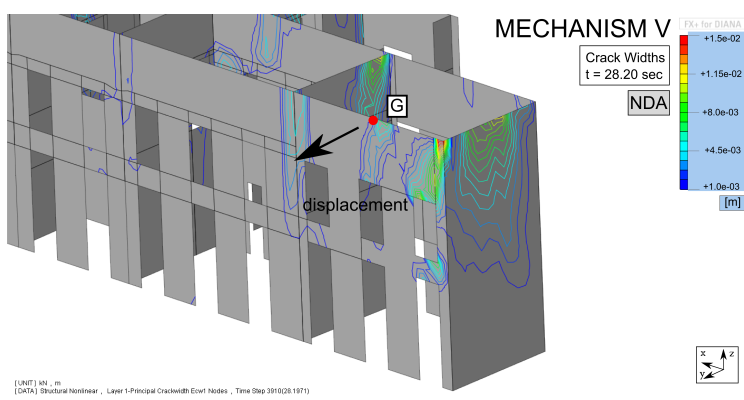

(a) NDA - mechanism V

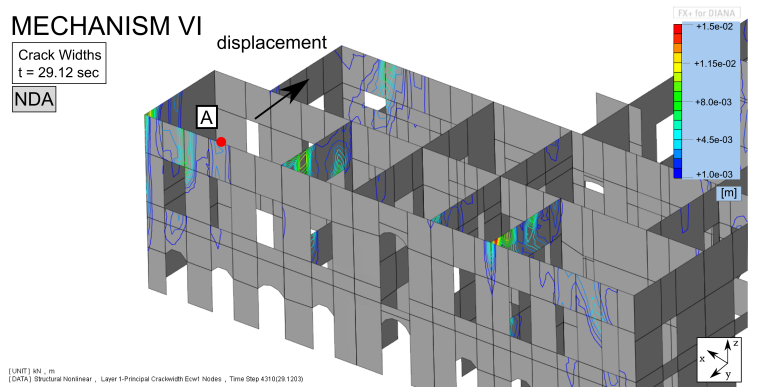

(c) NDA - mechanism VI

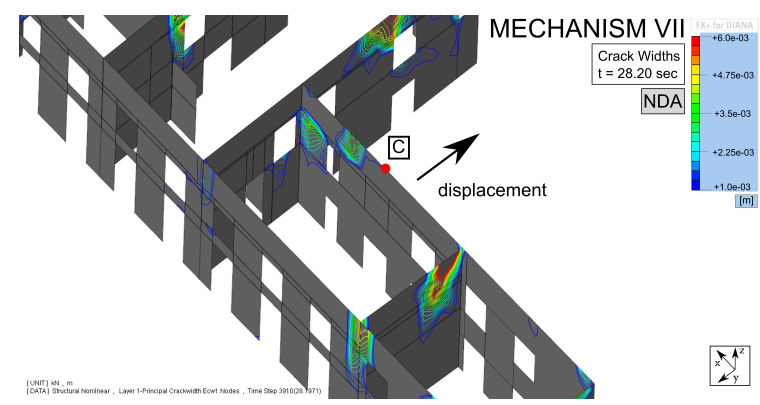

(e) NDA - mechanism VII

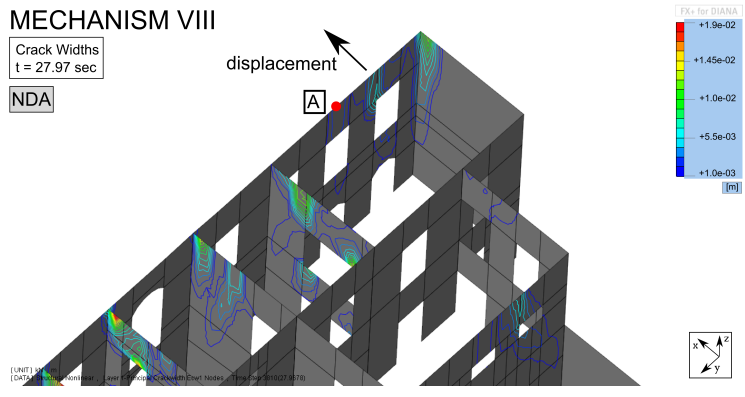

(g) NDA - mechanism VIII

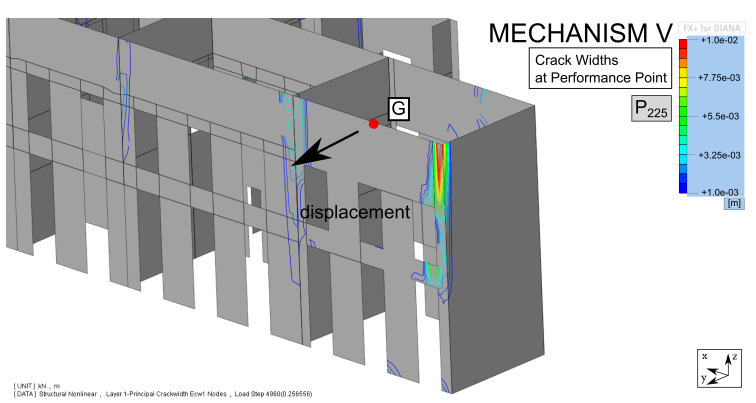

(b) NSA $\left(P_{225}\right)$ - mechanism V

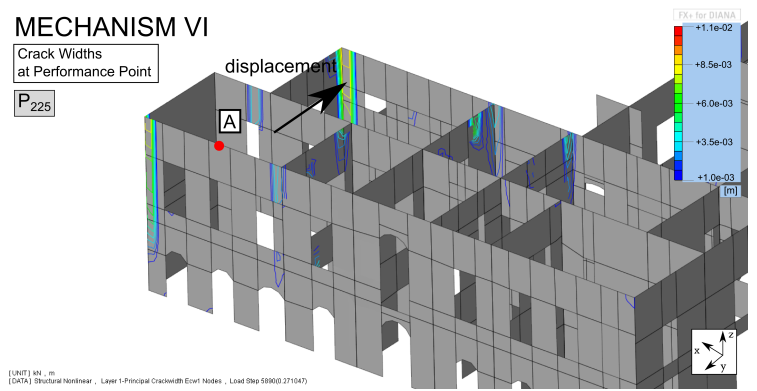

(d) NSA $\left(P_{225}\right)$ - mechanism VI

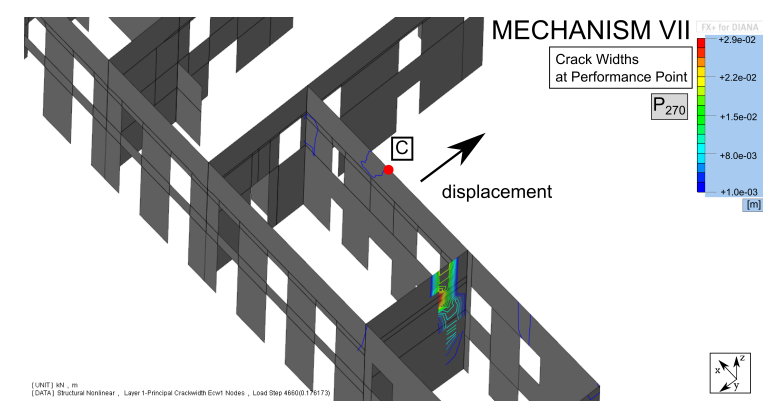

(f) NSA $\left(P_{270}\right)$ - mechanism VII

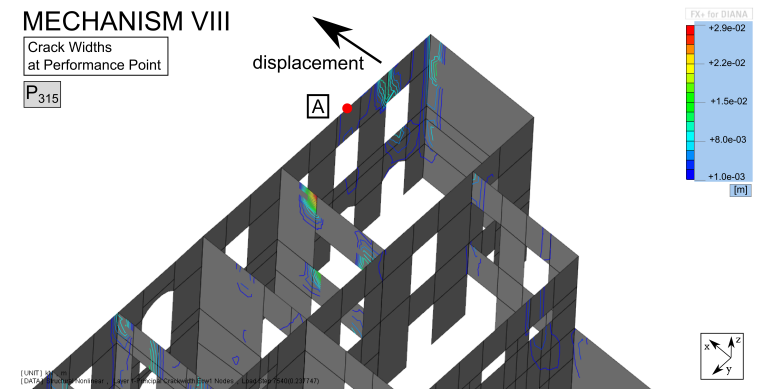

(h) NSA $\left(P_{315}\right)$ - mechanism VIII

Figure 23: Contour plots of the crack width larger than $1.0 \mathrm{~mm}$ for mechanisms $\mathrm{V}$ to VIII provided by the nonlinear dynamic and static analyses (NDA and NSA) 
analyses present cracks in the spandrels close to node G.

Mechanism IV (Figure 22g and 22h) is the out of plane overturning in negative $\mathrm{x}$-direction with control node D. Both the NDA and the $P_{225}$ NSA show cracks at the connections to the perpendicular walls.

Mechanism V (Figure 23a and 23b) displays an out of plane overturning in the negative $y$-direction of the facade at node G. For both the NDA and $P_{225}$ NSA large cracks appear at the corners with the perpendicular walls.

Mechanism VI (Figure 23c and 23d) shows the out of plane overturning in negative $\mathrm{x}$ direction at node $\mathrm{A}$. For both NDA and $P_{225}$ NSA large cracks appear in the corner. The cracks occurring in the spandrels of the perpendicular connected walls are less pronounced in the NSA than in the NDA.

Mechanism VII (Figure 23e and 23f) presents the local out of plane overturning in negative $y$-direction of the wall with control node $\mathrm{C}$ and appears both in the NDA and $P_{270}$ NSA. Large cracks in the perpendicular wall and the spandrels are correctly represented by both the analyses.

Mechanism VIII (Figure 23g and 23h) consists of large cracks in the corner and in the spandrels of the facade as well as in the perpendicular walls. The out of plane overturning of the wall is correctly provided by both the NDA and $P_{315}$ NSA.

Table 5 shows a visual summary of which mechanisms are detected by the NDA and the MDPA, respectively. It illustrates that the results of the NDA and the overall results of the proposed MDPA with eight loading directions are in a very good agreement. In particular, there is an important advantage offered by the MDPA compared with the conventional NSA along only the principal directions of the building. In fact, the execution of $P_{0}, P_{90}, P_{180}$ and $P_{270}$ only would exhibit only four different mechanisms (I, II, IV and VII), whilst the proposed MDPA displays a total of eight mechanisms. The novel MDPA approach allows to cover all the collapse mechanisms provided by the NDA.

\subsection{Comparison with 2010 Earthquake Damage}

The cracking patterns provided by MDPA and NDA are in agreement with those observed on the real structure after the 2010 earthquake. Figures 22a, 23c and 23g show several cracks in the spandrels of the south facade obtained by the NDA. Those are in agreement with the real ones shown in the Figure 6a. Figures 22c, 23a and $23 \mathrm{e}$ show cracks in the spandrels of the east facade, that are in agreement with those shown in Figure 6 b.
Table 5: Failure mechanisms detected by nonlinear dynamic and multi directional static analyses

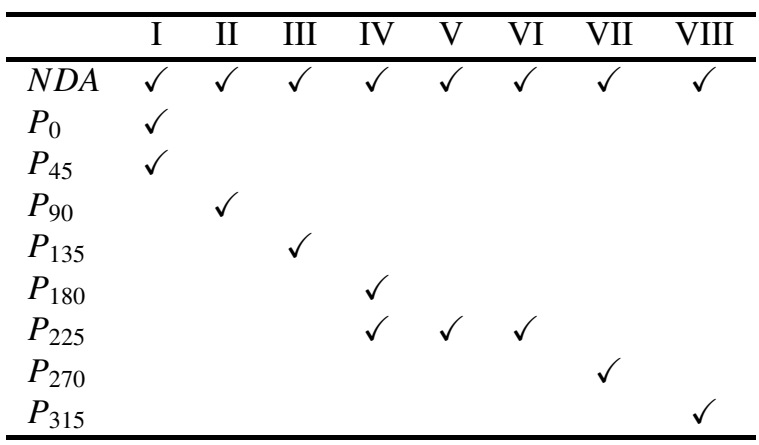

\section{Conclusions}

The present paper deals with a novel approach for the seismic analysis through the finite element method of irregular masonry structures without box behavior. Nonlinear dynamic analysis (NDA) is currently the most adequate tool for this type of structure. To avoid the wellknown large computational effort of nonlinear time history analysis, nonlinear static analysis (NSA) is usually carried out in seismic assessment. NSA generally exhibits significant limitations when dealing with irregular structures. This paper presents a novel multi directional pushover approach (MDPA) suitable to analyze existing buildings with plan and elevation irregularity, as well as without box behavior.

The proposed MDPA consists in performing sequentially a set of pushover analyses with mass proportional horizontal loading along eight directions with respect to the plan of the building. The approach breaks somehow one of the fundamental hypotheses of conventional NSA that consists in executing the pushover only along the principal directions of the masonry structure. The objective is to assess systematically the vulnerability of the structural members of the irregular building along a large set of lateral loading directions. This idea overcomes the limitations of conventional NSA that usually reveals to be unable to account for the multi directionality of the real earthquake motions. A masonry building with important irregularity in plan and elevation, and without box behavior, has been considered to show the advantages of the novel MDPA procedure. The case study is the Palacio Pereira in Chile, an historical palace damaged by an earthquake in 2010.

The modal analysis and response spectrum analysis (RSA) of the building have highlighted the tendency of the structure to vibrate in local parts due to its irregularity and deficient floor-to-wall connections. Several local modes describe the irregularity of the structure. 
The development of a MDPA has provided meaningful results about the assessment of the seismic behavior of the Palacio Pereira. The procedure has consisted in executing eight mass proportional pushover analyses by sequentially varying the loading direction of $45 \mathrm{de}$ grees in plan. The overall results of the MDPA have shown eight possible local failure mechanisms consisting on out-of-plane overturning of partial portions of the facades. It is worth noticing that the conventional approach of executing pushover analyses along the principal axes of the building would provide only four collapse mechanisms. The application of the new MDPA approach has led to the detection of four more local failure mechanisms of the structure than the ones obtained from a classical NSA approach. In addition, the average relative error of MDPA performance displacements, compared with NDA reference values for the different failure mechanisms, results moderate $(16.2 \%)$ and much lower than the average relative error of RSA displacements $(32.7 \%)$.

The NDA has been carried out by applying simultaneously the two perpendicular base accelerations of the 2010 Santiago de Chile earthquake. This analysis has shown several damage mechanisms in the structure during the base excitation. In particular, all the failure mechanisms provided by the NDA are equivalent to those reproduced by the MDPA.

The paper shows that a MDPA is a suitable procedure for the seismic analysis of irregular (in plan and in elevation) masonry buildings without box behavior. The main limitations of the standard pushover procedures applied to irregular structures can be overcome by considering the proposed MDPA since it shows to yield results more consistent with NDA. The selection of a meaningful case-study of a masonry building hit by an earthquake in 2010 has demonstrated that the MDPA overall results are also in agreement with real damage observations.

\section{Acknowledgements}

The second and third authors wish to thank the Chile- European Union Science, Technology and Innovation Initiative $(\mathrm{CEST}+\mathrm{I})$ "Working visits in Europe and Chile to elaborate project proposals and establish twinning mechanisms between institutions", funded by CONICYT (Chile), DLR (Germany), IDOM (Spain) and IRD (France). The research has received also the financial support from the Ministry of Science, Innovation and Universities (MCIU) of the Spanish Government, the State Agency of Research (AEI) and the European Regional Development Fund (ERDF) through the SEVERUS project (Multilevel evaluation of seismic vulnerability and risk mitigation of masonry buildings in resilient historical urban centres, ref. num. RTI2018-099589-B-I00). The third author also thanks the financial support given by the project FONDEF IDeA ID14I10187: Etapa 2. The support from "Secretaria d'Universitats i Investigació de la Generalitat de Catalunya" through a predoctoral grant awarded to the first author is also gratefully acknowledged.

\section{References}

[1] P. Roca, M. Cervera, G. Gariup, L. Pelà, Structural analysis of masonry historical constructions. classical and advanced approaches, Archives of Computational Methods in Engineering 17 (2010) 299-325. doi : 10.1007/s11831-010-9046-1.

[2] P. B. Lourenço, Computational strategies for masonry structures, Ph.D. thesis, Delft University of Technology (1996).

[3] D. V. Oliveira, P. B. Lourenço, Implementation and validation of a constitutive model for the cyclic behaviour of interface elements, Computers and Structures 82 (17-19) (2004) 1451-1461. doi:10.1016/j.compstruc. 2004.03.041.

[4] A. Drougkas, P. Roca, C. Molins, Analytical micro-modeling of masonry periodic unit cells - Elastic properties, International Journal of Solids and Structures 69-70 (2015) 169-188. doi: 10.1016/j.ijsolstr.2015.04.039.

[5] M. Petracca, L. Pelà, R. Rossi, S. Zaghi, G. Camata, E. Spacone, Micro-scale continuous and discrete numerical models for nonlinear analysis of masonry shear walls, Construction and Building Materials 149 (2017) 296-314. doi:10.1016/j. conbuildmat.2017.05.130.

[6] C. Sandoval, O. Arnau, Experimental characterization and detailed micro-modeling of multi-perforated clay brick masonry structural response, Materials and Structures 50 (34) (2017) 114. doi : 10.1617/s11527-016-0888-3.

[7] M. Betti, A. Vignoli, Numerical assessment of the static and seismic behaviour of the basilica of Santa Maria all'Impruneta (Italy), Construction and Building Materials 25 (12) (2011) 4308-4324. doi:10.1016/j. conbuildmat.2010.12.028.

[8] J. Carvalho, J. Ortega, P. B. Lourenço, L. F. Ramos, H. Roman, Safety analysis of modern heritage masonry buildings: Boxbuildings in Recife, Brazil, Engineering Structures 80 (2014) 222-240. doi:10.1016/j . engstruct. 2014.09.004.

[9] S. Saloustros, L. Pelà, P. Roca, J. Portal, Numerical analysis of structural damage in the church of the Poblet Monastery, Engineering Failure Analysis 48 (2015) 41-61. doi:10.1016/j. engfailanal.2014.10.015.

[10] H. Lotfi, P. Shing, An appraisal of smeared crack models for masonry shear wall analysis, Computers \& Structures 41 (3) (1991) 413-425. doi : 10.1016/0045-7949 (91) 90134-8. 
[11] P. B. Lourenço, R. De Borst, J. G. Rots, A plane stress softening plasticity model for orthotropic materials, International Journal for Numerical Methods in Engineering 40 (21) (1997) 4033-4057. doi:10.1002/(SICI) 1097-0207 (19971115) $40: 21<4033:$ : AID-NME248>3.0.CO;2-0.

[12] C. Calderini, S. Lagomarsino, A micromechanical inelastic model for historical masonry, Journal of Earthquake Engineering 10 (04) (2006) 453-479. doi:10.1080/ 13632460609350605 .

[13] L. Pelà, M. Cervera, P. Roca, An orthotropic damage model for the analysis of masonry structures, Construction and Building Materials 41 (2013) 957-967. doi:10.1016/j. conbuildmat.2012.07.014.

[14] Y. Endo, L. Pelà, P. Roca, Review of different pushover analysis methods applied to masonry buildings and comparison with nonlinear dynamic analysis, Journal of Earthquake Engineering 21 (8) (2017) 1234-1255. doi:10.1080/13632469.2016. 1210055 .

[15] S. Lagomarsino, S. Cattari, Seismic performance of historical masonry structures through pushover and nonlinear dynamic analyses, in: Perspectives on European Earthquake Engineering and Seismology, Springer, Cham, 2015, pp. 265-292. doi : 10.1007/978-3-319-16964-4_11.

[16] G. Milani, M. Valente, Failure analysis of seven masonry churches severely damaged during the 2012 Emilia-Romagna (Italy) earthquake: Non-linear dynamic analyses vs conventional static approaches, Engineering Failure Analysis 54 (2015) 13-56. doi : 10.1016/j.engfailanal .2015.03.016.

[17] Y. Endo, L. Pelà, P. Roca, F. da Porto, C. Modena, Comparison of seismic analysis methods applied to a historical church struck by 2009 L'Aquila earthquake, Bulletin of Earthquake Engineering 13 (2015) 3749-3778. doi:10.1007/ s10518-015-9796-0.

[18] W. Torres, J. L. Almazan, C. Sandoval, F. Peña, Fragility analysis of the nave macro-element of the Cathedral of Santiago, Chile, Bulletin of Earthquake Engineering 16 (7) (2018) 30313056. doi: 10.1007/s10518-017-0292-6.

[19] S. Degli Abbati, A. M. D’Altri, D. Ottonelli, G. Castellazzi, S. Cattari, S. de Miranda, S. Lagomarsino, Seismic assessment of interacting structural units in complex historic masonry constructions by nonlinear static analyses, Computers \& Structures 213 (2019) 51-71. doi:10.1016/j.compstruc.2018.12. 001.

[20] N. Mendes, P. B. Lourenço, Sensitivity analysis of the seismic performance of existing masonry buildings, Engineering Structures 80 (2014) 137-146. doi:10.1016/j.engstruct. 2014.09.005.

[21] N. Mendes, P. B. Lourenço, Seismic assessment of masonry "Gaioleiro" buildings in Lisbon, Portugal, Journal of Earthquake Engineering 14 (1) (2009) 80-101. doi:10.1080/ 13632460902977474 .

[22] P. B. Lourenço, N. Mendes, L. F. Ramos, D. V. Oliveira, Anal- ysis of masonry structures without box behavior, International Journal of Architectural Heritage 5 (4-5) (2011) 369-382. doi : $10.1080 / 15583058.2010 .528824$.

[23] European Committee for Standardization, Eurocode 8: Design provisions for earthquake resistance of structures, Part 1: General rules, seismic actions and rules for buildings. Brussels, CEN, 2004.

[24] P. Fajfar, A nonlinear analysis method for performance-based seismic design, Earthquake Spectra 16 (3) (2000) 573-592. doi:10.1193/1.1586128.

[25] S. Lagomarsino, D. Camilletti, S. Cattari, Seismic assessment of existing irregular masonry buildings by nonlinear static and dynamic analyses, in: Pitilakis K. (eds) Recent Advances in Earthquake Engineering in Europe. ECEE 2018. Geotechnical, Geological and Earthquake Engineering, vol 46, Springer, Cham, 2018, pp. 123-151. doi : 10.1007/978-3-319-75741-4_5.

[26] Y. Nakamura, H. Derakhshan, M. C. Griffith, G. Magenes, A. H. Sheikh, Applicability of nonlinear static procedures for lowrise unreinforced masonry buildings with flexible diaphragms, Engineering Structures 137 (2017) 1-18. doi:10.1016/j. engstruct.2017.01.049.

[27] V. Mallardo, R. Malvezzi, E. Milani, G. Milani, Seismic vulnerability of historical masonry buildings: A case study in Ferrara, Engineering Structures 30 (8) (2008) 2223-2241. doi: $10.1016 / \mathrm{j}$.engstruct. 2007.11 .006

[28] L. Avila, G. Vasconcelos, P. B. Lourenço, Experimental seismic performance assessment of asymmetric masonry buildings, Engineering Structures 155 (2018) 298-314. doi:10.1016/j. engstruct. 2017.10.059.

[29] N. C. Palazzi, L. Rovero, J. C. De La Llera, C. Sandoval, Preliminary assessment on seismic vulnerability of masonry churches in central chile, International Journal of Architectural Heritagedoi : $10.1080 / 15583058.2019 .1570388$.

[30] L. Pelà, A. Aprile, A. Benedetti, Seismic assessment of masonry arch bridges, Engineering Structures 31 (8) (2009) 1777-1788. doi: 10.1016/j. engstruct. 2009.02.012.

[31] P. Fajfar, D. Marušić, I. Peruš, Torsional effects in the pushover-based seismic analysis of buildings, Journal of Earthquake Engineering 9 (6) (2005) 831-854. doi:10.1080/ 13632460509350568.

[32] G.P. Cimellaro, T. Giovine , D. Lopez-Garcia , Bidirectional Pushover Analysis of Irregular Structures, Journal of Structural Engineering, ASCE 140 (9) (2014) 04014059-1 - 0401405913. doi : 10.1061/(ASCE) ST . 1943-541X.0001032.

[33] M. De Stefano, V. Mariani, Pushover analysis for plan irregular building structures, Perspectives on European Earthquake Engineering and Seismology (2014) 429-448doi:10.1007/ 978-3-319-07118-3_13.

[34] A. K. Chopra, R. K. Goel, A modal pushover analysis procedure to estimate seismic demands for unsymmetric-plan buildings, Earthquake Engineering and Structural Dynamics 33 (8) (2004) 
903-927. doi:10.1002/eqe.380.

[35] B. Gupta, S. K. Kunnath, Adaptive spectrabased pushover procedure for seismic evaluation of structures, Earthquake Spectra 16 (2) (2000) 367-392. doi : 10.1193/1.1586117.

[36] L. Luzi, F. Pacor, R. Puglia, Italian Accelerometric Archive v 2.3, Istituto Nazionale di Geofisica e Vulcanologia, Dipartimento della Protezione Civile Nazionale.doi:10.13127/ ITACA.2.3.

[37] C. Sandoval, R. Valledor, D. Lopez-Garcia, Numerical assessment of accumulated seismic damage in a historic masonry building. A case study, International Journal of Architectura Heritage 11 (8) (2017) 1177-1194. doi : 10.1080/15583058. 2017.1356945.

[38] R. Boroschek, P. Soto, R. Leon, Registros del Terremoto del Maule Mw $=8.8$ de 27 de Febrero de 2010, Informe RENADIC 10/05 Rev. 1, Departamento de Ingeniería Civil, Facultad de Ciencias Físicas y Matemáticas, Universidad de Chile (in Spanish).

[39] A. Camara, M. A. Astiz, Pushover analysis for the seismic response prediction of cable-stayed bridges under multidirectional excitation, Engineering Structures 41 (2012) 444455. doi:10.1016/j.engstruct.2012.03.059.

[40] J. C. Reyes, A. K. Chopra, Three-dimensional modal pushover analysis of buildings subjected to two components of ground motion, including its evaluation for tall buildings, Earthquake Engineering \& Structural Dynamics 40 (7) (2011) 789-806. doi:10.1002/eqe. 1060 .

[41] W. Huang, P. L. Gould, 3-D pushover analysis of a collapsed reinforced concrete chimney, Finite Elements in Analysis and Design 43 (2007) 879-887. doi:10.1016/j.finel.2007. 05.005 .

[42] F. Cannizzaro, B. Pantò, M. Lepidi, S. Caddemi, I. Caliò, Multidirectional seismic assessment of historical masonry buildings by means of macro-element modelling: Application to a building damaged during the L'Aquila earthquake (Italy), Buildings 7 (4) (2017) 106. doi:10.3390/buildings7040106.

[43] C. Chácara, P. B. Lourenço, F. Cannizzaro, B. Pantò, I. Caliò, Assessment of the seismic vulnerability of an unreinforced masonry structure based on discrete-macro dynamic analyses, in: R. Aguilar, D. Torrealva, S. Moreira, M. A. Pando, L. F. Ramos (Eds.), Structural Analysis of Historical Constructions, RILEM Bookseries 18, 2019, pp. 1210-1218. doi :10.1007/ 978-3-319-99441-3_130.

[44] S. Cattari, S. Marino, S. Lagomarsino, Seismic assessment of plan irregular masonry buildings with flexible diaphragms, in: Proceedings of the Tenth Pacific Conference on Earthquake Engineering, 2015, pp. 90-98.

[45] Ministero delle Infrastrutture e dei Trasporti. Circolare 21 gennaio 2019, 7. C.S.LL.PP. Istruzioni per l'applicazione dell` Norme tecniche per le costruzioni di cui al decreto ministeriale 17 gennaio 2018 (in Italian), Rome.
[46] European Committee for Standardization, Eurocode 8: Design provisions for earthquake resistance of structures, Part 3: Assessment and retrofitting of buildings. Brussels, CEN, 2005.

[47] TNO, DIANA - finite element analysis, User's manual, Release 10.2 (2017).

URL https://dianafea.com/manuals/d102/Diana. html

[48] ASCE, Seismic Rehabilitation of Existing Buildings, asce/sei 41-06 Edition, American Society of Civil Engineers, 2007. doi : 10.1061/9780784408841.

[49] R. Valledor, D. López-García, C. Sandoval, Linearly elastic seismic evaluation of masonry historical buildings in Santiago, Chile : The case of the Pereira Palace, in: 3rd International Conference on Mechanical Models in Structural Engineering, CMMoST, 2015, pp. 281-299.

URL http://hdl.handle.net/11441/36169

[50] Instituto Nacional de Normalización, NCh 433 Diseño sísmico de edificios - Earthquake resistant design of buildings (in Spanish), INN-Chile; Santiago, 2009.

[51] A. K. Chopra, Dynamics of Structures: Theory and Applications to Earthquake Engineering, Prentice-Hall, 1995. 